This document is confidential and is proprietary to the American Chemical Society and its authors. Do not copy or disclose without written permission. If you have received this item in error, notify the sender and delete all copies.

\title{
Small molecule inhibitors of metabolic enzymes repurposed as a new class of anthelmintics
}

\begin{tabular}{|c|c|}
\hline Journal: & ACS Infectious Diseases \\
\hline Manuscript ID & id-2018-00090t \\
\hline Manuscript Type: & Article \\
\hline Date Submitted by the Author: & 11-Apr-2018 \\
\hline Complete List of Authors: & $\begin{array}{l}\text { Tyagi, Rahul; Washington University in Saint Louis School of Medicine, } \\
\text { Medicine } \\
\text { Maddirala, Amarendar; Washington University in Saint Louis School of } \\
\text { Medicine, Department of Biochemistry and Molecular Biophysics } \\
\text { Elfawal, Mostafa; University of Massachusetts Medical School } \\
\text { Fischer, Chelsea; University of California San Francisco } \\
\text { Bulman, Christina; University of California San Francisco Department of } \\
\text { Pharmaceutical Chemistry } \\
\text { Rosa, Bruce; Washington University in Saint Louis School of Medicine, } \\
\text { Medicine } \\
\text { Gao, Xin; Washington University in Saint Louis School of Medicine, } \\
\text { Medicine } \\
\text { Chugani, Ryan ; Washington University in Saint Louis School of Medicine } \\
\text { Zhou, Mingzhou; Washington University in Saint Louis School of Medicine } \\
\text { Helander, Jon; Washington University in Saint Louis School of Medicine, } \\
\text { Medicine } \\
\text { Brindley, Paul; The George Washington University } \\
\text { Tseng, Chih-Chung; University of Aberdeen, } \\
\text { Greig, Iain; School of Medicine, Inst. If Medicine Sciences } \\
\text { Sakanari, Judy; University of California San Francisco Department of } \\
\text { Pharmaceutical Chemistry } \\
\text { Wildman, Scott; University of Wisconsin Madison, Carbone Cancer Center } \\
\text { Aroian, Raffi; University of Massachusetts Medical School } \\
\text { Janetka, James; Washington University School of Medicine, Department of } \\
\text { Biochemistry and Molecular Biophysics } \\
\text { Mitreva, Makedonka; Washington University in Saint Louis School of } \\
\text { Medicine, Medicine }\end{array}$ \\
\hline
\end{tabular}

\section{SCHOLARONE}




\section{Small molecule inhibitors of metabolic enzymes repurposed as a}

\section{new class of anthelmintics}

Rahul Tyagi ${ }^{1 \#}$, Amarendar Reddy Maddirala ${ }^{2 \#}$, Mostafa Elfawal ${ }^{3 \#}$, Chelsea Fischer ${ }^{4}$, Christina A. Bulman ${ }^{4}$, Bruce A. Rosa ${ }^{1}$, Xin Gao ${ }^{1}$, Ryan Chugani $^{2}$, Mingzhou Zhou $^{2}$, Jon Helander ${ }^{2}$, Paul J. Brindley $^{6}$, Chih-Chung Tseng ${ }^{7}$, lain R. Greig ${ }^{7}$, Judy Sakanari ${ }^{4}$, Scott A. Wildman ${ }^{5}$, Raffi Aroian ${ }^{3^{*}}$, James W. Janetka ${ }^{2^{*}}$ and Makedonka Mitreva $a^{1,8^{*}}$

${ }^{1}$ McDonnell Genome Institute, Washington University School of Medicine, 4444 Forest Park Ave, St. Louis, Missouri 63108, USA

${ }^{2}$ Department of Biochemistry and Molecular Biophysics, Washington University School of Medicine, 660 S. Euclid Ave., Box 8231, St. Louis, Missouri 63110, USA

${ }^{3}$ University of Massachusetts Medical School, Suite 219 Biotech 2, 373 Plantation St., Worcester, Massachusetts 01605, USA

${ }^{4}$ Department of Pharmaceutical Chemistry, University of California San Francisco, 1700 4th St, San Francisco, California 94158, USA

${ }^{5}$ UW Carbone Cancer Center, School of Medicine and Public Health, University of WisconsinMadison, 1111 Highland Ave., Madison, Wisconsin 53792, USA

${ }^{6}$ Department of Microbiology, Immunology \& Tropical Medicine, and Research Center for Neglected Diseases of Poverty, School of Medicine and Health Sciences, George Washington University, Ross Hall, Room 521, 2300 Eye Street, NW, Washington, DC 20037, USA

${ }^{7}$ Kosterlitz Centre for Therapeutics, University of Aberdeen, Foresterhill, Aberdeen, AB25 2ZD, U.K. ${ }^{8}$ Division of Infectious Diseases, Department of Medicine, Washington University School of Medicine, 4523 Clayton Ave., CB 8051, St. Louis MO, 63110, USA 
${ }^{\#}$ Equal contribution

*Corresponding authors : Raffi.Aroian@umassmed.edu (RA); janetkaj@wustl.edu (JJ); mmitreva@wustl.edu (MM).

ORCID

Makedonka Mitreva: 0000-0001-9572-3436 
The enormous prevalence of infections caused by parasitic nematodes worldwide, coupled to the rapid emergence of their resistance to commonly used anthelmintic drugs, presents an urgent need for the discovery of new drugs. Herein, we have identified several classes of small molecules with broad spectrum activity against these pathogens. Previously, we reported the identification of carnitine palmitoyltransferases (CPTs) as a representative class of enzymes as potential targets for metabolic chokepoint intervention that was elucidated from a combination of chemogenomic screening and experimental testing in nematodes. Expanding on these previous findings, we have discovered that several chemical classes of known small molecule inhibitors of mammalian CPTs have potent activity as anthelmintics. Cross-clade efficacy against a broad spectrum of adult parasitic nematodes was demonstrated for multiple compounds from different series. Several analogs of these initial hit compounds were designed and synthesized. The compounds we report represent a good starting point for further lead identification and optimization for development of new anthelmintic drugs with broad spectrum activity and a novel mechanism of action.

Keywords: Parasitic nematodes; hookworm, whipworm, filarial nematode, whole worm assay, in vitro, in vivo, target class repurposing, Carnitine palmitoyltransferase (CPT), bioaccumulation, anthelmintic. 
Parasitic nematodes (roundworms) are the causative agents responsible for multiple infectious diseases affecting over 2 billion people ${ }^{1}$, as well as contributing to loss of $10 \%$ of cultivated crops $^{2}$ and substantially reducing production of meat, milk and wool in domestic livestock ${ }^{3}$ worldwide. Although not commonly fatal in humans, these diseases significantly contribute to an enormous economic burden associated with lost productivity and perpetuation of poverty cycle ( $>3$ million years lived with disabilities (YLDs)) as well as imposing a heavy burden on associated healthcare costs. Indeed, they are among the most prevalent of parasitic diseases worldwide. The combination of the global healthcare burden, their prevalence, and lack of effective treatment options have led to their inclusion in the World Health Organization's (WHO) list of neglected tropical diseases. ${ }^{4}$

Mass drug administration (MDA) programs over the last two decades have led to a significantly reduced prevalence of some, but not all, of these diseases. Unfortunately, these efforts use only a small number of antiparasitic drug classes ${ }^{5}$, mostly benzimidazoles (e.g. albendazole), targeting tubulin in nematodes (intestinal infections) and macrocyclic lactones (e.g. ivermectin) targeting chloride ion channels, and used in combination with diethylcarbamazine (an inhibitor of arachidonic acid metabolism) for filarial MDAs ${ }^{6-7}$. Importantly, the large scale usage of these drugs has led to wide-spread resistance in parasitic nematodes of farm animals and concerns of similar resistance either crossing over or independently emerging in human parasites, which may already be occurring. ${ }^{8}$ In recent years, a limited number of new drugs with diverse mechanisms of action have been championed. These include the nicotinic receptor agonists (tribendimidine) or antagonists $(\text { monepantel })^{9}$ as well as a drug that has been proposed to target the protein kinase $\mathrm{C}$ signaling cascade (emodepside) $)^{10}$. However, none of these newly identified drugs are yet approved for use in humans, and resistance may quickly evolve against them, as shown for monepantel against the barber's pole worm Haemonchus contortus. ${ }^{11}$ Therefore, there is a pressing need to develop novel small molecule anthelmintics encompassing new modes of actions. 
One strategic opportunity to identify an entirely novel class of anthelmintic(s) is to target metabolic pathways essential to the viability of the parasites ${ }^{12-13}$. Given the accelerated pace and increased availability of genome scale information related to parasitic nematodes, it is possible to perform pan-phylum comparative analyses of genes and pathways involved, for example, with metabolism. ${ }^{13}$ These pan-phylum analyses have the potential to identify novel targets of essential metabolism and to guide the development of drugs with new modes of action with broad applicability across the diverse clades of the phylum Nematoda. This is desirable since co-infections with multiple parasitic species routinely occur, and economics disfavor the development of drugs for individual parasites. Previously, knowledge-based targeting of metabolic networks for pathogens has been used to identify novel candidates for drugs. ${ }^{14}$ Specifically, enzymes that either uniquely consume or produce a metabolite (termed "chokepoint" enzymes) have been targeted; inhibition of chokepoint activity is expected to be deleterious due to the absence of alternative pathways to compensate for their function. Similar approach at a much smaller scale has been applied to nematodes by this group ${ }^{12}$ where putative chokepoints in multiple species of worms were identified and a prioritization of both the individual chokepoint enzymes and their associated inhibitors in drug-target databases was performed.

The carnitine palmitoyltransferase (CPT) family of enzymes (EC 2.3.1.21) is a chokepoint in nematodes. CPTs are mitochondrial membrane-embedded enzymes that participate in transport of long chain fatty acids from the cytoplasm to the internal matrix of the mitochondrion, where they can be oxidized to release energy. Several classes of small molecule inhibitors have been described as CPTs were promising targets for type 2 diabetes and insulin resistance for many years ${ }^{15-16}$. Available chemical classes of inhibitors include oxirane carboxylic acids, which are irreversible covalent inhibitors and acylcarnitine analogs which are substrate competitive inhibitors. ${ }^{15}$ Further, homologous enzymes in humans have been reported to be targeted by perhexiline $(\mathrm{PHX}),{ }^{15}$ a marketed drug indicated for treatment of angina pectoris and ischemic heart disease.$^{17}$ In our previous work, we showed PHX to be effective against the early larval stages of Caenorhabditis elegans, the blood- 
feeding parasitic nematode $H$. contortus, and the filarial nematode Onchocerca lienalis. ${ }^{12}$ However, efficacy against adult parasites, which are the targets of chemotherapy, had not yet been shown.

To expand on our initial findings, we undertook a target class repurposing ${ }^{18}$ approach and tested known drug-like small molecule CPT inhibitors of the mammalian enzymes CPT1A, 1B and CPT2. To this end, we first purchased several compounds known to be CPT inhibitors and then synthesized representative examples of three other classes of heterocyclic CPT inhibitors that were not commercially available. Next, we developed a homology model of the nematode enzyme CPT2 and rationally designed analogs with modifications to selectively target nematode CPT2 over mammalian CPT2. We have systematically studied gene sequence variations (e.g., indels) among nematodes and hosts, where we identified variants specific to the phylum Nematoda. We subsequently characterized their structural impact on the variant proteins and then proposed their relevance to selective anthelmintic drug targeting. ${ }^{19}$ These compounds were synthesized and tested in vitro for their efficacy using phenotypic whole worm assays with a broad variety of nematode species having diverse modes of parasitism, including hookworms and whipworms, which reside within the lumen of the intestine, as well as filariids which live within the blood and solid tissues. PHX was further tested in an in vivo assay using hamsters infected with the intestinal zoonotic hookworm parasite, Ancylostoma ceylanicum.

\section{RESULTS AND DISCUSSION}

\section{Hit identification of initial compounds for targeting nematodes}

Two orthogonal approaches, both based on an underlying target class repurposing strategy, were followed to identify potential anthelmintics, based on existing mammalian CPT inhibitors. First, chemogenomic screening was performed to locate CPT homologs (Table S1) among the target proteins in the ChEMBL database using sequence similarity. This process identified 105 candidate compounds (Table S2), including PHX (P1 in Figure 1A) which has been reported to be active against 
the free living nematode $C$. elegans as well as larval stages of intestinal and filarial nematode parasites. $^{12} \mathbf{P} 1$ is a clinically used antianginal agent that weakly inhibits both CPT1 and CPT2 in humans, ${ }^{15}$ as well as other targets including certain $\mathrm{Ca}^{2+}$ and $\mathrm{K}^{+}$channels. ${ }^{20} \mathrm{~A}$ subset of these 105 compounds was selected by structural diversity, employing a stepwise scheme of prioritization. First, the compounds were clustered based on their fingerprint Tanimoto similarity scores ${ }^{21}$ and subsequently, compounds were rejected based on undesired physical properties ${ }^{22}$, lack of commercial availability, and cost. ${ }^{23}$ This filtering strategy resulted in the identification of nine compounds for testing in a whole organism phenotypic screen, of which five (P1-P5) were initially selected for screening (Figure $1 \mathrm{~A}$ and Table S3).

In a parallel second approach, four known small molecule inhibitors of mammalian CPT1A, 1B and CPT $2^{15}$ were synthesized (Schemes 1 and 2). These are compounds $6 \mathbf{a}, \mathbf{1 0 a}, \mathbf{1 7 a}$, and 17b. 6a and 10a belong to the phenoxyacetamide piperidinyl, and bis-phenylsulfonamide acid series of inhibitors, respectively. $17 \mathbf{a}$ and $\mathbf{1 7 b}$ (Scheme 2 ) are conformationally restricted analogs of the latter series which cyclize the sulfonamide into a fused ring. $\mathbf{6 a}$ is known to target rat and human CPT1A potently and selectively over CPT1B with some activity for CPT2. In contrast, 10a is less active for CPT1A and shows some activity for CPT1B and CPT2. 17a is 10-fold more potent inhibitor of CPT1A relative to $10 a$ and is totally selective over CPT1B, like $\mathbf{6 a}$. $17 \mathrm{~b}$ is similar to $10 \mathrm{a}$ since it has less CPT1A potency and is the most active against CPT1B. Of all compounds, $17 \mathrm{a}$ is the most active against CPT2. These compounds were chosen for synthesis and biological evaluation because they belong to four different chemical series in addition to their different selectivity profiles for the CPT isoforms.

\section{Compound screening with parasitic nematodes in a phenotypic motility assay}

The resulting nine compounds that we identified and prioritized were experimentally screened with five diverse species of parasitic nematodes that broadly span the phylum Nematoda by including representatives from three nematode clades $^{24}$ (Figure 2): Clade I (whipworm Trichuris muris), Clade 
III (filarial Brugia pahangi) and clade V (strongylids Ancylostoma ceylanicum, Nippostrongylus brasiliensis and Heligmosomoides polygyrus). For these tests, the adult developmental life cycle stages of each species were assayed. The adult stage of the worm generally represents the most relevant form for assessing their susceptibility to anthelmintic therapy and can display different responses from those of worms at the larval stages. This is particularly relevant for compounds that target metabolism, which can vary substantially during the developmental cycle of the nematode ${ }^{13}$. For example, larval stages of some soil transmitted helminths (STHs), such as hookworms, live in the soil, whereas the adult forms parasitize the GI tract of the mammalian host. These assays also included known anthelmintics as positive controls (pyrantel for hookworm and levamisole for whipworm) and a negative control (DMSO).

Three of the five compounds from the first set of candidate inhibitors (P1, P2, P5) showed deleterious effects on one or more parasitic species (Figure 2). It was gratifying to find that P1 (PHX) showed good potency against the worms but it is very structurally distinct from other known CPT modulators $^{15}$. Whereas it has long been thought that antianginal activity of PHX may be a direct consequence of its inhibition of CPT2 (or other unknown) activity, resulting in the fuel switch from fatty acid to glucose in the heart, PHX may cause more complex metabolic changes. ${ }^{25} \mathbf{P 2}$ showed selective activity against $T$. muris (whipworms) ${ }^{15,26-27}$ while P5 showed broad anthelmintic activity against both $A$. ceylanicum (hookworms) and whipworms. ${ }^{15}$ Of the synthesized analogs, $6 \mathbf{a}$ and $10 \mathbf{a}$ showed significant pan-nematode effects by decreasing the motility of the worms in more than one species. Finally, compound 17 a showed some activity against hookworms and the filarial species B. pahangi.

In summary, we found that six of the nine compounds tested were deleterious for one or more of the parasitic species (Table S4), and three of the six (P1, 6a, 10a) displayed pan-nematode effects (inhibiting at least one intestinal and a filarial species). P1 and 6a displayed the best pan-nematode effects in the whole worm assay by inhibiting multiple intestinal and filarial species and 10a was efficacious in only one intestinal species and a filarial species (Figure 2 and Table S4). 


\section{Expanding the list of small molecules with pan-phylum inhibition potential}

To expand on the structure activity relationships (SAR) of our hit compounds with the best panphylum inhibitory effect, we searched for available analogs. PHX is used in the clinic only in Australia, and New Zealand, but not elsewhere because of hepatic toxicity and peripheral neuropathy in patients with impaired metabolism resulting from polymorphism in the cytochrome P-450 enzyme (CYP2D6) which leads to high plasma concentrations of the drug. ${ }^{20}$ Recent findings revealed improved pharmacokinetic (PK) properties of synthetic fluorinated analogs of $\mathrm{PHX}{ }^{28}$ Thus, we acquired two of the PHX analogs (cycloalkyl analog P1a and fluorinated analog P1b) ${ }^{28}$ and experimentally screened them against a whipworm and a filariid nematode (Table S3 and Table S4). P1a significantly reduced activity in both the whipworm (60 $\mu \mathrm{M}$ at 24 and $48 \mathrm{hrs})$ and filarial worm (inhibition of worm motility of $99 \%$ with $75 \mu \mathrm{M}$ and $175 \mu \mathrm{M}$ within the first $24 \mathrm{hrs}$, day 0 ). Compound P1b completely inhibited the whipworm's motility after 48 hrs with $60 \mu \mathrm{M}$ and was similar to P1a in inhibiting filarial worm motility. While these analogs have improved pharmacokinetic properties, there was no effect on their anthelmintic activity relative to PHX.

In order to further understand our results from the phenotypic screening of the worms, we used compounds $6 \mathrm{a}$ and 10a to derive initial SAR (Figure 1B) through molecular modeling studies. As illustrated in Figure 3, we built a series of CPT2 homology models using an inhibitor-bound Rattus norvegicus (rat) X-ray crystal structure (PDB code: 2FW3), for four nematode species (T. muris, A. ceylanicum, C. elegans, Strongyloides stercoralis) and three mammalian hosts (Mus musculus, Mesocricetus auratus, Homo sapiens). Thereafter, we performed molecular docking studies using 6 a, 10a, 17a, and P1 (Figure 3B). We employed multiple parasitic nematode species for this analysis because CPT2 is conserved among nematodes, all orthologs of which are divergent from the mammalian ortholog (Table S5).

Based on this analysis derived from SAR and the molecular modeling studies, we rationally designed focused libraries based on $\mathbf{6 a}$ and $10 \mathbf{a}$ (Figure 4). Two modifications to $6 \mathbf{a}$ having the most 
productive effect were derivatives of the phenyl ether portion (Scheme 1A). Two additional analogs, $6 n$ and 60 were designed based on the overlay of $6 a$ with 10a and 17a (Figure 3B), both of which contain a phenyl carboxylic acid that makes an electrostatic interaction with the conserved histidine residue in human (His372), His571 in hookworm and His380 in whipworm. This was absent in 6a and was predicted to improve the binding affinity to CPT2 and improve potency in the motility assay. The methyl ester intermediates $\mathbf{6 I}$ and $\mathbf{6 m}$ were also tested for their activity. It was predicted that the methyl esters would increase permeability to the worms, acting as prodrugs and would hydrolyze into the predicted active carboxylic acid prior to engaging CPT1 or 2 in the mitochondrial membrane of the nematode cell. For $10 a$, we pursued changing the sulfonamide to a urea with three analogs 24a-c (Scheme 3) and also tested the methyl ester derivatives 23a-c as prodrugs of the carboxylic acid once again to assess differential effects in penetration of the nematode cuticle.

\section{Synthesis of compounds}

The synthesis of the small molecule inhibitors 6(a-k) are outlined in Scheme 1A (Figure S1S15). Reaction of compound $\mathbf{1}$ acid with ammonium chloride in presence of base yielding amide $\mathbf{2}$, which is converted to thioamide $\mathbf{3}$ by treating with Lawesson's reagent. The heterocyclic thiazole compound 4 were prepared by refluxing of compound 3 with appropriate 2-bromo (5-substituted pyridine)-1-one and $\mathrm{CaCO}_{3}$, which upon Boc-deprotection of intermediate 4 followed by coupling of appropriate acid yields 6(a-k). Compounds 10(a-c) were synthesized according to Scheme 1B (Figure S16-S18), where reaction of commercially available methyl-3-amino benzoate 8 with an appropriate 3,4-substituted benzene sulfonyl chloride $7(\mathrm{a}-\mathrm{c})$ in the presence of base, followed by ester hydrolysis yielded compounds $\mathbf{9 ( a - c ) . ~ I n ~ t u r n , ~ t h e s e ~ i n t e r m e d i a t e s ~ w e r e ~ c o u p l e d ~ w i t h ~ m e t h y l - 4 - ~}$ amino benzoate using standard amide bond coupling reagents EDCI/DIPEA/DMF. Subsequent hydrolysis of compounds $9(\mathrm{a}-\mathrm{c})$ yielded the final target compounds $10(\mathrm{a}-\mathrm{c})$.

The synthesis of inhibitors 17(a-b) is outlined in Scheme 2 (Figure S19-S20). Condensation of compounds 11(a-b) with aryl sulfonyl chlorides 12(a-b) in presence of base (pyridine) yields 
sulfonamide intermediates $13(a-b)$. The methyl esters were converted to the carboxylic acids $14(a-b)$ by basic hydrolysis, followed by coupling with amines 15 (a-b) using EDC/DIPEA/DMF. The resulting amides 16(a-b) were hydrolyzed to provide the final targets $17(a-b)$. Compounds $24(a-c)$ are functionally distinct analogs of compounds $10(\mathbf{a}-\mathbf{c})$ in which the sulfonamide group is replaced by a urea. These were synthesized (Scheme 3; Figure S21-S26) by coupling of amine 18 with 3-nitro benzoyl chloride 19 which furnished intermediate 20. Next, sequential catalytic reduction of both protecting groups yielded aniline 21. Installation of the urea group was accomplished via reaction with isocyanates 22(a-c) giving intermediate esters $\mathbf{2 3}(\mathbf{a}-\mathrm{c})$, which were hydrolyzed to give the carboxylic acids 24(a-c).

\section{Biological evaluation of rationally designed nematode inhibitors}

We tested the new analogs for broad spectrum potential by screening three species spanning the phylum (Table S5): two intestinal parasites (Clade V - A. ceylanicum and Clade I - T. muris) and a filarial parasite (Clade III - B. pahangi). Three of the 10 analogs of $\mathbf{6 a}(\mathbf{6 c}, \mathbf{d}, \mathbf{j})$ were effective against T. muris and B. pahangi whereas 23a-c and 24a-c (analogs of 10a) had only a speciesspecific effect with efficacy against the filarial nematode, B. pahangi. In addition, as evidenced by the $\mathrm{IC}_{50}$ values, two analogs $(\mathbf{6 c}, \mathbf{d})$ were much more potent compared to $6 \mathbf{a}$ (Table S4) against both B. pahangi (14 and 11 vs. $96 \mu \mathrm{M})$ and T. muris (118 and 32 vs. $195 \mu \mathrm{M})$. Time- and speciesdependent $\mathrm{IC}_{50}$ values are provided in Figure S27.

The compounds 6I-o were designed (Figures 3 and 4) to incorporate a carboxylic acid, as observed from docking analyses to make an electrostatic or $\mathrm{H}$-bonding interaction with His 372 of CPT2 like that of the benzoic acid of $10 a, 17 a$ and $17 \mathbf{b}$. In addition to the carboxylic acids $(6 \mathbf{n}$ and 6o), the methyl esters (6I and $\mathbf{6 m}$ ) were prepared as prodrugs thought to increase penetration of the worm outer cuticle. Interestingly, only the methyl esters $6 \mathbf{I}$ and $\mathbf{6 m}$ showed any noticeable activity, with the most active of the four, $6 \mathrm{~m}$, requiring $250 \mu \mathrm{M}$ and $175 \mu \mathrm{M}$ concentrations to inhibit motility for 
T. muris and $B$. pahangi, respectively, at 48 hours. The free acids had negligible activity on either $B$. pahangi or T. muris (Table S4), possibly indicating poor cuticle permeability.

\section{Differential activity is potentially related to worm cuticle membrane penetration and uptake}

One possible explanation for the differential phenotypic activity of the compounds tested among intestinal species may be differential penetration of the cuticle between species. Bioaccumulation assays (Figure S28-44) of P1, 6a and 10a by LC-MS of lysates of $T$. muris after incubation with these compounds clearly detected P1 and 6a using the $210 \mathrm{~nm}$ channel and MS identification of the parent compound, but not 10a (Table S6 and Figure S28-S44). This would support that activity in $T$. muris results from this differential uptake of these compounds into the worm.

In B. pahangi, neither compound 6a nor 10a was observed at the incubation concentrations used, both having $\mathrm{IC}_{50}$ values less than $100 \mu \mathrm{M}$; however, $6 \mathbf{f}$, which has negligible activity, was present in high quantities. P1 (and analogs P1a and P1b) was observed; however, it was observed near the limit of detection, likely due to low concentrations used and weak recovery. The pro-drug compounds $\mathbf{6 I}$ and $\mathbf{6 m}$ were observed in much higher abundance than their free-acid counterparts $\mathbf{6 n}$ and 6o, respectively, supporting the hypothesis that uptake into the cuticle may benefit by increasing hydrophobicity of the compounds.

\section{In vivo activity of Perhexiline in hookworm-infected hamsters}

To ascertain whether our newly discovered class of pan-nematode chokepoint inhibitors possessed therapeutic utility in parasitic nematodes, Syrian hamsters (Mesocricetus auratus) infected with A. ceylanicum were treated with $\mathrm{PHX}(\mathbf{P 1})$ at $100 \mathrm{mg} / \mathrm{kg}$ per os. Although the treatment had no marked effect on the worm load, there was a significant reduction in A. ceylanicum eggs/gram of feces compared to untreated control (Figure $5 \mathrm{~A}$ and $\mathrm{B}$ ). This result suggested that the target of $\mathbf{P 1}$ (either a CPT isoform or another target) may interfere with reproduction in hookworms at the concentration resulting from this treatment or that generalized intoxication of the parasites in vivo led 
to a reduction in reproduction. Pertinent and consistent with the former, metabolic enzymes like CPT are essential for oocyte development in mammals, ${ }^{29}$ and beta-oxidation plays a critical role in egg production in schistosomes, a flatworm parasite of mammals. ${ }^{30}$ The observation that $\mathbf{P} 1$ causes significant impaired egg production is supported by the RNAseq based developmental gene expression profiles of CPTs in A. ceylanicum which shows lower expression of CPT1/2 in L4 female compared to adult female and compared to L4 male and adult males (Figure $5 \mathrm{C}$ and D). CPT expression in tissues of Ascaris suum (intestinal nematode large enough to perform facile tissue dissection) also shows much higher expression in ovary compared to both uterus in female worms and the seminal vesicle and testis in males (Figure S45; A. suum RNAseq normalized expression values are from Rosa et al, 2014). ${ }^{31}$ The in vivo screening results and the RNAseq expression profiles support the overall observation that the $\mathbf{P} 1$ target plays a critical role in egg production.

\section{CONCLUSIONS}

Nematode parasites have evolved over millions of years to occupy a wide variety of ecological and trophic niches. Nematoda is an ancient phylum with the estimated time since last common ancestors with other animal phyla being traced to the Cambrian explosion $\sim 550$ million years ago. ${ }^{32-33}$ As the consequence of this complex natural history, discovery of drugs that exhibit activity against a broad spectrum of species of parasitic nematodes that are only very distantly related to each other is challenging. Nonetheless, there is a pressing need for novel, broadly effective anthelmintics, especially given that multiple concurrent infections occur in many regions. ${ }^{34}$ Here, starting with a single compound perhexiline (PHX) that has been reported to display pan-phylum potential as antiparasitic by Taylor et al. 2013, ${ }^{12}$ we identified diverse classes of chemical compounds that are effective against an array of divergent nematodes encompassing different modes of parasitism intestinal and tissue-dwelling. These inhibitors display in vitro whole worm assay $\mathrm{IC}_{50}$ values similar to anthelmintics that are currently most commonly used. ${ }^{35}$ Notably, even though anthelmintic activity 
have not been previously attributed to these compounds, many of the prioritized compounds that we rationally selected for screening displayed significant anthelmintic activity against one or more species of nematodes.

Herein, Iwe have shown that several series of previously known CPT modulators and newly designed compounds significantly affect the motility and viability of several types of parasitic worms in phenotypic assays of worm motility. It remains unclear whether the relative differences among species is a result of variable inhibition of the nematode CPT enzymes or is due to differential outer membrane penetration of the worms. Since, we only performed phenotypic screening on whole worms, it is plausible that one or more of these new chemical series of nematode inhibitors do not target CPTs and the effect is derived from other biological targets or activities. However, our findings from drug bioaccumulation screening suggest that some inactive analogs are incapable of penetrating the cuticle of the nematode. This knowledge can be directed at improving uptake of inhibitors through the neamtode cuticle and used to optimize the compounds for potency.

To conclude, we report the discovery of multiple series of small molecules as novel anthelmintics with pan-phylum anti-nematode activity. Following a rationally guided repurposing strategy of small molecule human CPT inhibitors, we have successfully identified several new chemical classes of pan-nematode inhibitors. Since our data were generated via phenotypic screening, additional investigation is needed to identify their mechanism of action. It is possible that the different chemical series might have diverse targets, some of which may include nematode CPT enzymes. Nevertheless, our results from this study now enable and facilitate the optimization of these lead novel small molecule inhibitors as innovative drugs to treat a variety of debilitating diseases caused by parasitic worms.

\section{METHODS}

\section{Ethics statement}


All animal experiments were carried out under protocols approved by University of Massachusetts Medical School (UMMS; A-2483 and A-2484) Institutional Animal Care and Use Committees (IACUC). All housing and care of laboratory animals conformed to the National Institutes of Health (NIH) Guide for the Care and Use of Laboratory Animals in Research (see 18-F22) and all requirements and all regulations issued by the United States Department of Agriculture (USDA), including regulations implementing the Animal Welfare Act (P.L. 89-544) as amended (see 18-F23). Euthanasia was accomplished by $\mathrm{CO}_{2}$ asphyxiation, followed by bilateral pneumothorax.

\section{Identifying known small molecule CPT modulators}

CPT orthologs were identified using orthoMCL ${ }^{36}$ over predicted proteomes of 23 species. The proteomes selected belonged to 14 nematodes - including STHs, filariids and strongylids - and nine outgroup species (Table S1). An inflation factor of 1.5 was used. CPT genes of C. elegans were used to identify CPT orthologs in the other species. Normalized $A$. ceylanicum CPT expression levels for Fig. 5C and 5D were extracted from developmental global expression profile table available at Nematode.net ${ }^{37}$ and normalized A. suum CPT expression levels for Figure S1 were extracted from Rosa et al, $2014 .^{31}$

CPT orthologs among the target proteins in ChEMBL database v18 were identified using BLAST (e-10, 50\% identity) identifying 105 ChEMBL compounds targeting these proteins (Table S2). Compound clustering was accomplished based on structural similarity using FP2 fingerprints in Open Babel (v2.3). ${ }^{38}$ The physicochemical score was assigned based on an approach reported previously, $^{12}$ with a minimum score of 4 being required for selection. Information on commercial availability of test compounds was sourced from the ZINC database. ${ }^{39}$

Homology models were built for four worm and three mammalian host species using Molecular Operating Environment software (Chemical Computing Group, Montreal, version 2014.09). CPT sequences from the nematodes T. muris, A. ceylanicum, $C$. elegans, S. stercoralis and the mammals M. musculus, $M$. auratus, and $H$. sapiens, were aligned with the crystal structures from $R$. norvegicus 
CPT2 (2FW3).$^{40}$ This structure includes the ligand teglicar ${ }^{41}$ in the binding site. The homology models were built individually, with the teglicar atoms included to maintain reasonable binding site geometry. Each model was energy minimized using the AMBER10 force field. ${ }^{42}$ Resulting models were compared to several other rat CPT2 crystal structures (2DEB, 2FYO, 2H4T, 4EP9, 4EPH, 4EYW) with no significant differences in the region of the binding site. Ligand docking to any of the models was done using FRED (OpenEye Scientific Software, Santa Fe, version 3.0.1), followed by energy minimization in the AMBER10 force field.

\section{Compound screening with intestinal nematodes}

A. ceylanicum: In vitro assays were carried out as previously described. ${ }^{35}$ Three adult worms were manually sorted into each wells of 96 -well plate, containing culture medium and the test drug (4 wells/test drug). Primary CPT inhibitors were tested against hookworm at 1, 3, 10,40 and $80 \mu \mathrm{g} / \mathrm{ml}$ in $1 \%$ DMSO. Analogs of $6 \mathrm{a}$ and $10 \mathrm{a}$ were tested at $250 \mu \mathrm{M} \square$ and $125 \mu \mathrm{M}$. Worms were scored for motility after 24 hours of incubation at $37^{\circ} \mathrm{C}$ and $5 \% \mathrm{CO}_{2}$.

T. muris: In vitro assays were carried out as described. ${ }^{35}$ Four worms were manually sorted into each well of 24-well plates ( 3 wells/ test drugs). Primary CPT inhibitors were tested against whipworms at 40 and $80 \mu \mathrm{g} / \mathrm{ml}$ and the analogs of $6 \mathrm{a}$ and $10 \mathrm{a}$ were tested at $250 \mu \mathrm{M} \square$ and $125 \mu \mathrm{M}$. Worms were scored for motility after 48 hours of incubation at $37^{\circ} \mathrm{C}$ and $5 \% \quad \mathrm{CO}_{2}$. IC50 determinations were conducted at $500 \mu \mathrm{M}, 250 \mu \mathrm{M}, 125 \mu \mathrm{M}, 62.5 \mu \mathrm{M}, 31.25 \mu \mathrm{M}, 15.6 \mu \mathrm{M}, 7.8 \mu \mathrm{M}$, $3.9 \mu \mathrm{M}, 1.9 \mu \mathrm{M}, 0 \mu \mathrm{M}$. IC50 values at 48 hours were used to establish a non-linear regression using Prism 7 (Graphpad, La Jolla, CA). All T. muris IC50s listed displayed $\mathrm{R}^{2}$ values $\geq 0.8$.

H. polygyrus: 4 weeks old Swiss Webster mice (females) were infected by stomach gavage with infective L3 of $H$. polygyrus, 15 days post infection parasites were harvested from the small intestine and four worms were manually sorted into each well of 96-well plates (three wells/ test 
drugs) containing nematode culture medium and test drugs at 80 and $40 \mu \mathrm{g} / \mathrm{ml}$ in $1 \%$ DMSO. Worms were scored for motility after 72 hours of incubation at $37^{\circ} \mathrm{C}$ and $5 \% \mathrm{CO}_{2}$.

$N$. brasiliensis: 5 weeks old laboratory rats were infected with iL3 of $N$. brasiliensis by the subcutaneous route. Six days post infection, the rats were euthanized and parasites were harvested from the small intestine and four worms were manually sorted into each well of 96-well plates (four wells/ test drugs) containing nematode culture medium and test drugs at 80 and $40 \mu \mathrm{g} / \mathrm{ml}$ in $1 \%$ DMSO. Worms were scored for motility after 48 hours of incubation at $37^{\circ} \mathrm{C}$ and $5 \% \mathrm{CO}_{2}$.

Ex vivo drug activity was determined using the standard motility index ranging from $0-3$ as previously described. ${ }^{35}$ Motility index of 3 were given to vigorous worms, 2 for motile worms, 1 for motile after stimulation by touching, and 0 for dead worms.

\section{Compound screening with the filarial nematode B. pahangi}

Adult female B. pahangi worms were obtained from Dr. Brenda Beerntsen, University of Missouri, Columbia, MO. Individual females were placed in each well of a 24 -well plate in culture

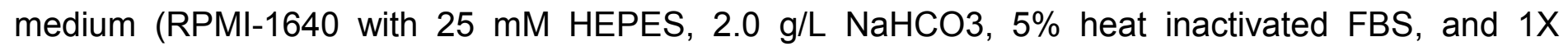
Antibiotic/Antimycotic solution). Excess medium was removed, leaving $500 \mu \mathrm{L}$ in each well.

Fresh powders of the seven known CPT inhibitors that were synthesized (6a, 10a-c and 17ab) were dissolved in DMSO (Fisher Scientific, Fair Lawn, NJ). Initial screening of the compounds was performed at $100 \mu \mathrm{M}$ and at $20 \mu \mathrm{M}$. Four worms were used as replicates at each concentration. Worms treated with $1 \%$ DMSO only served as the negative control. The cultures were maintained at $37^{\circ} \mathrm{C}, 5 \% \mathrm{CO}_{2}$ incubator for seven days; the duration of the assay.

The Worminator, a visual imaging software system developed and described previously was used to determine the effect of each treatment on worm motility. ${ }^{43}$ Movements of individual worms were calculated by determining the number of pixels displaced per second per well. Worm movements were averaged over the time of recording (60 seconds) and mean movement units 
(MMUs) were determined for individual worms. Percent inhibition of motility was calculated by dividing the MMUs of the treated worms by the average MMUs of the $1 \%$ DMSO treated control worms, subtracting the value from 1.0 , flooring the values to zero and multiplying by $100 \%$. Videos of the worms during the assay were recorded on days $0,1,2,3$, and 6 of the incubation. Compounds showing $\geq 75 \%$ inhibition of motility at either concentration on day 3 of the assay were investigated further using $\mathrm{IC}_{50}$ assay. Compounds $6 \mathrm{a}$ and $10 \mathrm{a}$ at $100 \mu \mathrm{M}$ fit this criterion, inhibiting worm motility $95 \%$ and $100 \%$, respectively, on day $3 . \mathrm{IC}_{50}$ determinations were conducted at $100 \mu \mathrm{M}, 30 \mu \mathrm{M}, 10$ $\mu \mathrm{M}, 3 \mu \mathrm{M}, 1 \mu \mathrm{M}, 0.3 \mu \mathrm{M}$. Worms were treated in the same fashion as above and motility was measured each day for three days using the Worminator. IC50 values on day 2 was used to establish a non-linear regression curve fit, using Prism 7 (Graphpad, La Jolla, CA). All Brugia IC ${ }_{50}$ s listed in Table $S 4$ all displayed $R^{2}$ values $\geq 0.8$.

\section{Bioaccumulation assays}

T. muris: Twelve adult T. muris worms were placed into three worms/well. The wells contained the drug at a final concentration of $100 \mu \mathrm{M}$ in $1 \%$ DMSO. After 6 hours of incubation, the worms were placed into clean plates containing saline and washed twice. This was followed by three more washes using $0.1 \%$ SDS to remove drugs from the surface. The worms were then placed into an Eppendorf tube and washed twice using saline and centrifuged to form a pellet, which was stored overnight at $20^{\circ} \mathrm{C}$. At the time of assay, the worms were frozen in liquid Nitrogen, crushed using pestles and incubated with $100 \mu \mathrm{L}$ of $1 \mathrm{x}$ lysis buffer with proteinase $\mathrm{K}$ for $60 \mathrm{~min}$ at $60^{\circ} \mathrm{C}$. Two $\mu \mathrm{L}$ of the worm digestant was used to measure the total protein content using BCA protein kit. The proteins from the remaining digestant were precipitated using $100 \mu \mathrm{L}$ of acetonitrile. The supernatant $(\sim 180 \mu \mathrm{L})$ was stored at $-80^{\circ} \mathrm{C}$. The lysates were analyzed for levels of each individual compound by HPLC/MS analysis. DMSO was used as the negative control while $\mathbf{P 1}$, which is known to be membrane permeable, was used as the positive control. 
Lysates were analyzed on a Hewlett Packard Series 1100 HPLC, using a Sunfire $C_{18} 3.5 \mu \mathrm{m}$ pore-size, $4.6 \times 50 \mathrm{~mm}$ column. Samples were injected with $10 \mu \mathrm{L}$ of volume with a flow rate of 1 $\mathrm{mL} / \mathrm{min}$, and solvent system of $\mathrm{H}_{2} \mathrm{O}(0.01 \%$ TFA $)$ and acetonitrile $(0.05 \%$ TFA). Gradient was $0 \rightarrow 5$ minutes: $5-95 \%$ linear increase acetonitrile, $5 \rightarrow 6$ minutes $95 \%$ acetonitrile hold, $6 \rightarrow 7$ minutes $95-5 \%$ linear decrease acetonitrile. Elution was monitored by 210 and $254 \mathrm{~nm}$ UV-absorption and by MS. MS conditions were drying gas $12 \mathrm{~L} / \mathrm{min}$, drying gas temperature $350^{\circ} \mathrm{C}$, nebulizer psig $55-60$, and capillary voltage $4000 \mathrm{~V}$. Compound presence was evaluated by extracting $[\mathrm{M}+\mathrm{H}]^{+}$or $[\mathrm{M}+\mathrm{Na}]^{+}$of parent compound mass.

B. pahangi: Adult female B. pahangi worms were prepared for in vitro culture as described above and treated in vitro for 72 hours. Upon collection worms were washed twice in $0.1 \%$ SDS, followed by 1 wash in culture media, then frozen in culture media at $-20^{\circ} \mathrm{C}$. To prepare lysates for bioaccumulation assays, worms were thawed on ice, media was removed, and three to four worms were pooled together. Worms were then washed once with PBS, frozen in liquid nitrogen and crushed with pestles. Lysates were prepared as described for T. muris above, with the exception that worms were incubated at $60^{\circ} \mathrm{C}$ for 5 hours.

\section{Perhexiline A. ceylanicum in vivo assay}

Experiments were conducted essentially as previously described. ${ }^{35,44}$ Five weeks old golden Syrian hamsters were infected with 100 iL3 of A. ceylanicum. Infected rodents were grouped based on the fecal egg count on day 18 post infection. One group was treated with single oral dose of 100 $\mathrm{mg} / \mathrm{kg}$ Perhexiline (1) whereas the other group (control) was dosed only with water. Fecal samples were collected 20 days post infection (p.i) for fecal egg count. On day 21 p.i., the hamsters were euthanized and the small intestine opened longitudinally. Adult parasites within the intestine were counted under a dissecting microscope. 


\section{COMPOUND SYNTHESIS}

\section{General Methods}

Starting materials, reagents, and solvents were purchased from commercial vendors unless otherwise noted. In general, anhydrous solvents were used for carrying out all reactions. ${ }^{1} \mathrm{H}$ and ${ }^{13} \mathrm{C}$ NMR spectra were measured on a Varian $400 \mathrm{MHz}$ NMR instrument equipped with an auto sampler. The chemical shifts were reported as $\delta \mathrm{ppm}$ relative to TMS using residual solvent peak as the reference unless otherwise noted. The following abbreviations denote the peak multiplicities: $s=$ singlet; $\mathrm{d}=$ doublet; $\mathrm{t}=$ triplet; $\mathrm{q}=$ quartet; $\mathrm{m}=$ multiplet; $\mathrm{br}=$ broad. All reactions were monitored by thin layer chromatography (TLC) carried out on either Merck silica gel plates (0.25 mm thick, 60F254) and visualized by using UV (254 nm) or dyes such as phosphomolybdic acid. Silica gel chromatography was carried out on a Teledyne ISCO CombiFlash purification system using prepacked silica gel columns (4 g-24 g sizes).

\section{General procedures}

\section{General procedure for compounds 6a and 6f: Method A}

Compound $4 \mathrm{a}^{45}(0.180 \mathrm{~g}, 0.52 \mathrm{mmol})$ was dissolved in trifluoroacetic acid $(1 \mathrm{~mL})$, stirred $1 \mathrm{~h}$, then concentrated in vacuo to provide intermediate $\mathbf{5 a}$, which was dissolved in anhydrous $\mathrm{DCM}(2 \mathrm{~mL})$ and the solution was bubbled with argon $2 \mathrm{~min}$, then triethylamine $(0.29 \mathrm{~mL}, 2.1 \mathrm{mmol})$ and DMAP $(0.006$ g, $0.05 \mathrm{mmol})$ were added, followed by phenoxyacetyl chloride $(0.072 \mathrm{~mL}, 0.52 \mathrm{mmol})$. The mixture was stirred $24 \mathrm{~h}$ at $\mathrm{RT}$, then washed with water, then brine, dried with $\mathrm{Na}_{2} \mathrm{SO}_{4}$, and concentrated in vacuo, after which it was purified by silica gel chromatography with ethyl acetate/hexanes combinations as eluent, giving rise to the title compound $\mathbf{6 a}$.

\section{General procedure for compounds 6(b-e) \& 6(g-k): Method B}


CDI (66 mg, $0.4 \mathrm{mmol})$ was added into a solution of 2-phenoxyacetic acid $(31 \mathrm{mg}, 0.2 \mathrm{mmol})$ in DCM (2 $\mathrm{mL})$ and solution was stirred for $30 \mathrm{~min}$ at room temperature; thereafter, solution of (R)-2(piperidin-2-yl)-4-(pyridin-2-yl, $\mathbf{5 a}^{45}(50 \mathrm{mg}, 0.2 \mathrm{mmol})$ in DCM $(1 \mathrm{~mL})$ was added and the reaction solution stirred for $24 \mathrm{~h}$. Progress of the reaction was monitored by TLC and upon completion of the reaction, reaction mass diluted with $\mathrm{DCM}(10 \mathrm{~mL})$, washed with $10 \%$ citric acid, followed by saturated $\mathrm{NaHCO}_{3}$ and brine. The organic layer was dried over anhydrous $\mathrm{Na}_{2} \mathrm{SO}_{4}$. Solvent was evaporated under reduced pressure and the crude compound was subjected for column chromatography.

\section{General procedure for compounds 6(I-m): Method C}

To a solution of 2-phenoxy acetic acid $(120 \mathrm{mg}, 0.57 \mathrm{mmol})$, there was added HOBt $(231 \mathrm{mg}, 1.71$ $\mathrm{mmol}$ ) and EDC (265 mg, $1.71 \mathrm{mmol}, 3 \mathrm{eq})$ at $0^{\circ} \mathrm{C}$ in $20 \mathrm{~mL}$ of THF, and allowed to stir for 15 minutes. To this solution there was then added the amine $5 \mathrm{a}(135 \mathrm{mg}, 0.57 \mathrm{mmol})$ and triethylamine $(99 \mu \mathrm{L}, 0.7 \mathrm{mmol})$. The solution was allowed to stir overnight and reach room temperature. The reaction was then diluted with EtOAc, and washed with $1 \mathrm{M} \mathrm{HCl}$, brine, and dried over $\mathrm{Na}_{2} \mathrm{SO}_{4}$. The ester was purified by silica gel column chromatography using EtOAc/hexanes to provide the compounds $\mathbf{6}(\mathrm{I}-\mathrm{m})$. The methyl ester $\mathbf{6}(\mathrm{I}-\mathrm{m})$ was dissolved in methanol/water $(1: 1 \mathrm{v} / \mathrm{v})$ and three equivalents of $\mathrm{LiOH}$ were added and the solution stirred until the methyl ester was fully hydrolyzed. The majority of the methanol was removed in vacuo and the resulting solution was extracted with EtOAc, dried with $\mathrm{Na}_{2} \mathrm{SO}_{4}$, and concentrated under reduced pressure. The crude compounds were purified by silica gel column chromatography using EtOAc/hexanes to provide the compounds $\mathbf{6}(\mathbf{m}$ o).

(R)-2-phenoxy-1-(2-(4-(pyridin-2-yl)thiazol-2-yl)piperidin-1-yl)ethan-1-one (6a)<smiles>O=C(COc1ccccc1)N1CCCCC1c1nc(-c2ccccn2)cs1</smiles> 
Compound synthesized as per method A, white solid with $170 \mathrm{mg}$ in $86 \%$ yield; ${ }^{1} \mathrm{H}$ NMR $(400 \mathrm{MHz}$, $\left.\mathrm{CD}_{3} \mathrm{Cl}\right) \delta \mathrm{ppm} 8.94(\mathrm{~d}, J=5.5 \mathrm{~Hz}, 1 \mathrm{H}), 8.57(\mathrm{~s}, 1 \mathrm{H}), 8.31-8.23(\mathrm{~m}, 1 \mathrm{H}), 8.14(\mathrm{t}, J=7.4 \mathrm{~Hz}, 1 \mathrm{H})$, $7.56(\mathrm{t}, J=6.3 \mathrm{~Hz}, 1 \mathrm{H}), 6.05(\mathrm{~d}, J=4.7 \mathrm{~Hz}, 1 \mathrm{H}), 4.76(\mathrm{~s}, 2 \mathrm{H}), 3.91(\mathrm{~d}, J=13.3 \mathrm{~Hz}, 1 \mathrm{H}), 3.21(\mathrm{t}, J=$ $12.7 \mathrm{~Hz}, 1 \mathrm{H}), 2.51(\mathrm{~d}, J=13.7 \mathrm{~Hz}, 1 \mathrm{H}), 1.93-1.79(\mathrm{~m}, 1 \mathrm{H}), 1.77-1.58(\mathrm{~m}, 3 \mathrm{H}), 1.58-1.35(\mathrm{~m}, 1 \mathrm{H})$ (rotamers); LCMS (ESI): found [M + H] $]^{+}, 380.3$.

(R)-2-([1,1'-biphenyl]-4-yloxy)-1-(2-(4-(pyridin-2-yl)thiazol-2-yl)piperidin-1-yl)ethan-1-one (6b).<smiles>O=C(COc1ccc(-c2ccccc2)cc1)N1CCCCC1c1nc(-c2ccccc2)cs1</smiles>

Compound synthesized as per method B, white solid with $37 \mathrm{mg}$ in $40 \%$ yield; ${ }^{1} \mathrm{H}$ NMR $(400 \mathrm{MHz}$, $\left.\mathrm{CD}_{3} \mathrm{Cl}\right) \delta$ ppm 9.15 (br. s., $1 \mathrm{H}$ ), 8.63-8.52 (m, $\left.1 \mathrm{H}\right), 8.23$ (d, $\left.J=7.8 \mathrm{~Hz}, 1 \mathrm{H}\right), 7.52$ (br. s., $\left.4 \mathrm{H}\right), 7.47$ (br. s., $1 \mathrm{H}), 7.45-7.36(\mathrm{~m}, 3 \mathrm{H}), 7.36-7.28(\mathrm{~m}, 1 \mathrm{H}), 7.08(\mathrm{~d}, J=8.2 \mathrm{~Hz}, 2 \mathrm{H}), 6.99(\mathrm{~d}, J=8.6 \mathrm{~Hz}, 1$ H), $6.14(\mathrm{~d}, J=4.3 \mathrm{~Hz}, 1 \mathrm{H}), 4.88(\mathrm{~d}, J=3.1 \mathrm{~Hz}, 2 \mathrm{H}), 3.98(\mathrm{~d}, J=16.8 \mathrm{~Hz}, 1 \mathrm{H}), 3.46-3.30(\mathrm{~m}, 1 \mathrm{H})$, 2.72-2.52 (m, $1 \mathrm{H}), 2.29-2.01(\mathrm{~m}, 3 \mathrm{H}), 1.94$ (dd, $J=18.2,6.1 \mathrm{~Hz}, 2 \mathrm{H}), 1.80$ (br. s., $3 \mathrm{H}$ ), 1.72 (br. s., $1 \mathrm{H}), 1.68-1.49(\mathrm{~m}, 2 \mathrm{H}), 1.35-1.17(\mathrm{~m}, 2 \mathrm{H}), 0.93-0.77(\mathrm{~m}, 1 \mathrm{H})($ rotamers); LCMS (ESI): found [M + $\mathrm{H}]^{+}, 456.3$.

(R)-2-(naphthalen-1-yloxy)-1-(2-(4-(pyridin-2-yl)thiazol-2-yl)piperidin-1-yl)ethan-1-one (6c).<smiles>O=C(COc1cccc2ccccc12)N1CCCCC1c1nc(-c2ccccn2)cs1</smiles>

Compound synthesized as per method $\mathrm{B}$, white solid with $32 \mathrm{mg}$ in $41 \%$ yield; ${ }^{1} \mathrm{H}$ NMR $(400 \mathrm{MHz}$, $\mathrm{CD}_{3} \mathrm{Cl}$ ) $\delta$ ppm 9.14 (br. s., $1 \mathrm{H}$ ), 8.57 (br. s., $\left.1 \mathrm{H}\right), 8.32$ (d, J = $\left.7.4 \mathrm{~Hz}, 1 \mathrm{H}\right), 8.24-8.10(\mathrm{~m}, 1 \mathrm{H}), 7.83$ (d, $J=6.7 \mathrm{~Hz}, 1 \mathrm{H}), 7.60-7.45(\mathrm{~m}, 4 \mathrm{H}), 7.45-7.31(\mathrm{~m}, 4 \mathrm{H}), 6.95(\mathrm{~d}, J=6.3 \mathrm{~Hz}, 1 \mathrm{H}), 6.17$ (br. s., 1 H), 5.11-4.94 (m, $2 \mathrm{H}), 4.21-4.00(\mathrm{~m}, 1 \mathrm{H}), 3.49-3.27(\mathrm{~m}, 1 \mathrm{H}), 2.70-2.56(\mathrm{~m}, 1 \mathrm{H}), 1.83-1.67(\mathrm{~m}, 3 \mathrm{H})$, 1.67-1.46 (m, $1 \mathrm{H}), 1.27$ (br. s., $1 \mathrm{H})\left(\right.$ rotamers); LCMS (ESI): found $[\mathrm{M}+\mathrm{H}]^{+}, 430.3$.

\section{2-(naphthalen-2-yloxy)-1-((2R)-2-(4-(pyridin-2-yl)-4,5-dihydrothiazol-2-yl)piperidin-1-yl)ethan-1- one (6d).}<smiles>O=C(COc1ccc2ccccc2c1)N1CCCCC1c1nc(-c2ccccn2)cs1</smiles> 
Compound synthesized as per method $\mathrm{B}$, white solid with $18 \mathrm{mg}$ in $41 \%$ yield; ${ }^{1} \mathrm{H}$ NMR $(400 \mathrm{MHz}$, $\left.\mathrm{CD}_{3} \mathrm{Cl}\right) \delta$ ppm 9.28 (br. s., $\left.1 \mathrm{H}\right), 8.71(\mathrm{~d}, J=4.3 \mathrm{~Hz}, 1 \mathrm{H}), 8.57(\mathrm{~d}, J=8.2 \mathrm{~Hz}, 1 \mathrm{H}), 7.84-7.74(\mathrm{~m}, 2 \mathrm{H})$, 7.74-7.52 (m, $4 \mathrm{H}), 7.48-7.29(\mathrm{~m}, 3 \mathrm{H}), 7.26-7.10(\mathrm{~m}, 3 \mathrm{H}), 6.15(\mathrm{~d}, J=5.1 \mathrm{~Hz}, 1 \mathrm{H}), 4.96(\mathrm{~s}, 2 \mathrm{H})$, $4.08(\mathrm{~d}, J=13.3 \mathrm{~Hz}, 1 \mathrm{H}), 3.35(\mathrm{t}, J=12.7 \mathrm{~Hz}, 1 \mathrm{H}), 2.65-2.51(\mathrm{~m}, 1 \mathrm{H}), 2.03-1.87(\mathrm{~m}, 1 \mathrm{H}), 1.86-$ $1.68(\mathrm{~m}, 3 \mathrm{H}), 1.68-1.49(\mathrm{~m}, 1 \mathrm{H})$ (rotamers); LCMS (ESI): found [M + Na] ${ }^{+}$, 430.3 .

\section{2-(4-((3R,5R,7R)-adamantan-1-yl)phenoxy)-1-((R)-2-(4-(pyridin-2-yl)thiazol-2-yl)piperidin-1-} yl)ethan-1-one (6e).<smiles>O=C(COc1ccc(C23CC4CC(CC(C4)C2)C3)cc1)N1CCCCC1c1nc(-c2ccccn2)cs1</smiles>

Compound synthesized as per method B, white solid with $24 \mathrm{mg}$ in $46 \%$ yield; ${ }^{1} \mathrm{H}$ NMR $(400 \mathrm{MHz}$, $\mathrm{CD}_{3} \mathrm{Cl}$ ) $\delta$ ppm 9.14 (br. s., $1 \mathrm{H}$ ), 8.58 (br. s., $1 \mathrm{H}$ ), 8.20 (d, J = $\left.7.0 \mathrm{~Hz}, 1 \mathrm{H}\right), 7.52(\mathrm{~s}, 1 \mathrm{H}), 7.42-7.32$ $(\mathrm{m}, 1 \mathrm{H}), 7.23(\mathrm{~d}, J=7.8 \mathrm{~Hz}, 1 \mathrm{H}), 6.95(\mathrm{~d}, J=8.2 \mathrm{~Hz}, 1 \mathrm{H}), 6.87(\mathrm{~d}, J=7.4 \mathrm{~Hz}, 1 \mathrm{H}), 6.12$ (br. s., 1 H), $4.80(\mathrm{~d}, J=7.4 \mathrm{~Hz}, 2 \mathrm{H}), 3.95(\mathrm{~d}, J=12.9 \mathrm{~Hz}, 1 \mathrm{H}), 3.43-3.28(\mathrm{~m}, 1 \mathrm{H}), 2.62(\mathrm{~d}, J=11.7 \mathrm{~Hz}, 1 \mathrm{H})$, 2.09 (br. s., $4 \mathrm{H}$ ), 1.97-1.80 (m, 10H), 1.26 (br. s., $5 \mathrm{H}$ ), 0.88 (d, J=10.2 Hz, $1 \mathrm{H}$ )(rotamers); LCMS (ESI): found $[\mathrm{M}+\mathrm{Na}]^{+}, 514.4$.

(R)-2-(4-methoxyphenoxy)-1-(2-(4-(pyridin-2-yl)thiazol-2-yl)piperidin-1-yl)ethan-1-one (6f).<smiles>COc1ccc(-c2csc([C@@H]3CCCCN3C(=O)COc3ccccc3)n2)nc1</smiles>

Compound synthesized as per method A, white solid with, $176 \mathrm{mg}$ in $86 \%$ yield; ${ }^{1} \mathrm{H}$ NMR $(400 \mathrm{MHz}$, $\left.\mathrm{CD}_{3} \mathrm{Cl}\right) \delta \mathrm{ppm} 7.83(\mathrm{~d}, J=8.2 \mathrm{~Hz}, 2 \mathrm{H}), 7.37-7.27(\mathrm{~m}, 2 \mathrm{H}), 7.26-7.20(\mathrm{~m}, 1 \mathrm{H}), 7.05-6.91(\mathrm{~m}, 5 \mathrm{H})$, 6.12 (br. s., $1 \mathrm{H}), 4.94-4.76(\mathrm{~m}, 2 \mathrm{H}), 3.91(\mathrm{~d}, J=13.3 \mathrm{~Hz}, 1 \mathrm{H}), 3.86(\mathrm{~s}, 3 \mathrm{H}), 3.38(\mathrm{t}, J=13.1 \mathrm{~Hz}, 1$ H), $2.62(\mathrm{~d}, J=12.1 \mathrm{~Hz}, 1 \mathrm{H}), 2.08-1.91(\mathrm{~m}, 1 \mathrm{H}), 1.84(\mathrm{~d}, J=14.1 \mathrm{~Hz}, 1 \mathrm{H}), 1.73(\mathrm{~d}, J=12.5 \mathrm{~Hz}, 2$ $\mathrm{H}), 1.65-1.56(\mathrm{~m}, 1 \mathrm{H}), 1.56-1.39(\mathrm{~m}, 1 \mathrm{H})$ (rotamers); LCMS (ESI): found [M + H] ${ }^{+}, 410.4$.

(R)-2-(4-cyclohexylphenoxy)-1-(2-(4-(pyridin-2-yl)thiazol-2-yl)piperidin-1-yl)ethan-1-one (6g).<smiles>O=C(COc1ccc(C2CCCCC2)cc1)N1CCCC[C@H]1c1nc(-c2ccccn2)cs1</smiles> 
Compound synthesized as per method B, white solid with $21 \mathrm{mg}$ in $45 \%$ yield; ${ }^{1} \mathrm{H}$ NMR (400 MHz, $\mathrm{CD}_{3} \mathrm{Cl}$ ) $\delta$ ppm 9.13 (br. s., $1 \mathrm{H}$ ), 8.58 (br. s., $1 \mathrm{H}$ ), 8.28-8.03 (m, $1 \mathrm{H}$ ), 7.52 (br. s., $1 \mathrm{H}$ ), 7.36 (br. s., 1 H), 7.22 -7.02 (m, $2 \mathrm{H}), 7.02-6.88(\mathrm{~m}, 1 \mathrm{H}), 6.85$ (br. s., $1 \mathrm{H}), 6.12$ (br. s., $1 \mathrm{H}), 4.76$ (br. s., $2 \mathrm{H}), 3.96$ (d, J = 9.0 Hz, 1 H), $2.63(\mathrm{~d}, J=10.6 \mathrm{~Hz}, 1 \mathrm{H}), 2.54-2.25(\mathrm{~m}, 1 \mathrm{H}), 1.83$ (br. s., $5 \mathrm{H}), 1.76$ (br. s., $4 \mathrm{H}$ ), 1.37 (br. s., $6 \mathrm{H}$ ), 1.26 (br. s., $6 \mathrm{H}$ ), 0.87 (d, J=10.6 Hz, $1 \mathrm{H}$ )(rotamers); LCMS (ESI): found [M + H] ${ }^{+}$, 462.4 .

(R)-2-(4-benzylphenoxy)-1-(2-(4-(pyridin-2-yl)thiazol-2-yl)piperidin-1-yl)ethan-1-one (6h).<smiles>O=C(COc1ccc(Cc2ccccc2)cc1)N1CCCC[C@H]1c1nc(-c2ccccn2)cs1</smiles>

Compound synthesized as per method B, white solid with $24 \mathrm{mg}$ in $50 \%$ yield; ${ }^{1} \mathrm{H} \mathrm{NMR}(400 \mathrm{MHz}$, $\left.\mathrm{CD}_{3} \mathrm{Cl}\right) \delta$ ppm9.34 (br. s., $\left.1 \mathrm{H}\right), 8.79-8.64(\mathrm{~m}, 2 \mathrm{H}), 7.85-7.74(\mathrm{~m}, 1 \mathrm{H}), 7.67(\mathrm{~s}, 1 \mathrm{H}), 7.35-7.29(\mathrm{~m}, 1$ H), 7.25-7.02 (m, $5 \mathrm{H}), 6.93(\mathrm{~d}, J=8.2 \mathrm{~Hz}, 1 \mathrm{H}), 6.11(\mathrm{~d}, J=4.3 \mathrm{~Hz}, 1 \mathrm{H}), 4.81$ (br. s., $2 \mathrm{H}), 3.99$ (d, J $=14.1 \mathrm{~Hz}, 1 \mathrm{H}), 3.95-3.85(\mathrm{~m}, 2 \mathrm{H}), 3.27(\mathrm{t}, J=12.9 \mathrm{~Hz}, 1 \mathrm{H}), 2.55-2.68(\mathrm{~m}, 1 \mathrm{H}), 2.11-1.87(\mathrm{~m}, 1 \mathrm{H})$, 1.83-1.53 (m, $4 \mathrm{H})$ (rotamers); LCMS (ESI): found [M + H $]^{+}, 470.4$.

(R)-2-((4'-methyl-[1,1'-biphenyl]-4-yl)oxy)-1-(2-(4-(pyridin-2-yl)thiazol-2-yl)piperidin-1-yl)ethan-1one (6i).<smiles>Cc1ccc(-c2ccc(OCC(=O)N3CCCCC3c3nc(-c4ccccn4)cs3)cc2)cc1</smiles>

Compound synthesized as per method B, white solid with $12 \mathrm{mg}$ in $42 \%$ yield; ${ }^{1} \mathrm{H}$ NMR $(400 \mathrm{MHz}$, $\mathrm{CD}_{3} \mathrm{Cl}$ ) $\delta$ ppm 9.13 (br. s., $1 \mathrm{H}$ ), 8.56 (br. s., $1 \mathrm{H}$ ), 8.23-8.13 (m, $\left.1 \mathrm{H}\right), 7.59$ (br. s., $\left.1 \mathrm{H}\right), 7.51$ (d, J = 7.0 Hz, $3 \mathrm{H}), 7.47-7.39(\mathrm{~m}, 3 \mathrm{H}), 7.39-7.30(\mathrm{~m}, 2 \mathrm{H}), 7.26-7.15(\mathrm{~m}, 3 \mathrm{H}), 7.06(\mathrm{~d}, \mathrm{~J}=7.4 \mathrm{~Hz}, 1 \mathrm{H})$, 7.03-6.88 (m, $1 \mathrm{H}), 6.14$ (br. s., $1 \mathrm{H}), 4.87$ (br. s., $2 \mathrm{H}), 3.98$ (d, J = 5.5 Hz, $1 \mathrm{H}), 3.44-3.32(\mathrm{~m}, 1 \mathrm{H})$, 2.77-2.53 (m, $1 \mathrm{H}), 2.39$ (br. s., $4 \mathrm{H}), 1.91-1.67$ (m, $3 \mathrm{H}), 0.96-0.77$ (m, 4H)(rotamers); LCMS (ESI): found $[\mathrm{M}+\mathrm{H}]^{+}, 470.4$.

(R)-2-(4-(pyridin-2-yl)phenoxy)-1-(2-(4-(pyridin-2-yl)thiazol-2-yl)piperidin-1-yl)ethan-1-one (6j) 
<smiles>O=C(COc1ccc(-c2ccccn2)cc1)N1CCCC[C@H]1c1nc(-c2ccccn2)cs1</smiles>

Compound synthesized as per method $\mathrm{B}$, white solid with $50 \mathrm{mg}$ in $41 \%$ yield; ${ }^{1} \mathrm{H} \mathrm{NMR}(400 \mathrm{MHz}$, $\mathrm{CD}_{3} \mathrm{Cl}$ ) $\delta$ ppm9.13 (br. s., $1 \mathrm{H}$ ), 8.66 (br. s., $1 \mathrm{H}$ ), 8.56 (br. s., $\left.1 \mathrm{H}\right), 8.17$ (d, J = 6.7 Hz, $1 \mathrm{H}$ ), $7.85-8.01$ $(\mathrm{m}, 2 \mathrm{H}), 7.80-7.62(\mathrm{~m}, 2 \mathrm{H}), 7.52$ (br. s., $1 \mathrm{H}), 7.35$ (br. s., $1 \mathrm{H}), 7.21$ (br. s., $1 \mathrm{H}), 7.10(\mathrm{~d}, \mathrm{~J}=7.8 \mathrm{~Hz}$, $1 \mathrm{H}), 7.02$ (d, J = 7.0 Hz, $1 \mathrm{H}), 6.13$ (br. s., $1 \mathrm{H}), 4.08-3.90(\mathrm{~m}, 1 \mathrm{H}), 3.38(\mathrm{t}, \mathrm{J}=12.7 \mathrm{~Hz}, 1 \mathrm{H}), 2.73-$ $2.56(\mathrm{~m}, 1 \mathrm{H}), 2.03(\mathrm{~d}, J=18.4 \mathrm{~Hz}, 2 \mathrm{H}), 1.97-1.86(\mathrm{~m}, 1 \mathrm{H}), 1.78$ (br. s., $2 \mathrm{H}), 1.70$ (br. s., $1 \mathrm{H}), 1.65-$ $1.45(\mathrm{~m}, 1 \mathrm{H}), 1.26$ (br. s., $2 \mathrm{H})(\text { rotamers); LCMS (ESI): found [M + H] }]^{+}, 457.3$.

(R)-1-(2-(4-(naphthalen-2-yl)thiazol-2-yl)piperidin-1-yl)-2-phenoxyethan-1-one (6k)<smiles>O=C(COc1ccccc1)N1CCCCC1c1nc(-c2ccc3ccccc3c2)cs1</smiles>

Compound synthesized as per method B, white solid with $20 \mathrm{mg}$ in $50 \%$ yield; ${ }^{1} \mathrm{H}$ NMR (400 MHz, $\left.\mathrm{CD}_{3} \mathrm{Cl}\right) \delta$ ppm $8.45(\mathrm{~s}, 1 \mathrm{H}), 8.03(\mathrm{~d}, J=8.6 \mathrm{~Hz}, 1 \mathrm{H}), 7.93-7.82(\mathrm{~m}, 4 \mathrm{H}), 7.53-7.43(\mathrm{~m}, 2 \mathrm{H}), 7.30-$ $7.20(\mathrm{~m}, 1 \mathrm{H}), 7.14(\mathrm{t}, J=7.6 \mathrm{~Hz}, 1 \mathrm{H}), 7.02(\mathrm{~d}, J=7.8 \mathrm{~Hz}, 1 \mathrm{H}), 6.95(\mathrm{~d}, J=7.8 \mathrm{~Hz}, 2 \mathrm{H}), 6.08(\mathrm{~d}, J=$ $4.3 \mathrm{~Hz}, 1 \mathrm{H}), 5.07-4.91(\mathrm{~m}, 2 \mathrm{H}), 3.95(\mathrm{~d}, J=13.7 \mathrm{~Hz}, 1 \mathrm{H}), 3.41(\mathrm{t}, J=13.1 \mathrm{~Hz}, 1 \mathrm{H}), 2.72-2.47(\mathrm{~m}$, $1 \mathrm{H}), 2.03-1.90(\mathrm{~m}, 1 \mathrm{H}), 1.83-1.61$ (m, $4 \mathrm{H})$ (rotamers); LCMS (ESI): found [M + H] ${ }^{+}, 429.3$

(R)-2-((4-methylbenzoate)phenoxy)-1-(2-(4-(pyridin-2-yl)thiazol-2-yl)piperidin-1-yl)ethan-1-one (6I)<smiles>CC(=O)c1ccc(OCC(=O)N2CCCCC2c2nc(-c3ccccn3)cs2)cc1</smiles>

Compound synthesized as per method $\mathrm{C}$, white solid with $140 \mathrm{mg}$ in $65 \%$ yield. ${ }^{1} \mathrm{H} \mathrm{NMR}(400 \mathrm{MHz}$, $\left.\mathrm{CD}_{3} \mathrm{OD}\right) \delta$ ppm: 9.39-9.12 (m, 1H), 9.04-8.81 (m, 1H); 8.77-8.66 (m, 1H), 8.39-8.21 (m, 1H), 8.06-7.71 $(\mathrm{m}, 3 \mathrm{H}), 7.10-6.84(\mathrm{~m}, 2 \mathrm{H}), 6.10-5.20(\mathrm{~m}, 1 \mathrm{H}), 5.10(\mathrm{~m}, 2 \mathrm{H}), 4.50-3.90(\mathrm{~m}, 1 \mathrm{H}), 3.87-3.77(\mathrm{~m}, 3 \mathrm{H})$, $3.30(\mathrm{~m}, 1 \mathrm{H}), 2.98-1.46(\mathrm{~m}, 7 \mathrm{H})$ (rotamers); LCMS (ESI): found $[\mathrm{M}+\mathrm{H}]^{+}, 438.3$

(R)-2-(3-methylbenzoatephenoxy)-1-(2-(4-(pyridin-2-yl)thiazol-2-yl)piperidin-1-yl)ethan-1-one $(6 \mathrm{~m})$ 
<smiles>COC(=O)c1cccc(OCC(=O)N2CCCCC2c2nc(-c3ccccn3)cs2)c1</smiles>

Compound synthesized as per method $\mathrm{C}$, white solid with $135 \mathrm{mg}, 63 \%$ yield. ${ }^{1} \mathrm{H} \mathrm{NMR}(400 \mathrm{MHz}$, $\left.\mathrm{CD}_{3} \mathrm{OD}\right) \delta$ ppm 9.17-9.02 (m, 1H), 8.53-8.43 (m, 1H), $8.35(\mathrm{~m}, 1 \mathrm{H}), 8.11-7.96(\mathrm{~m}, 1 \mathrm{H}), 7.67-7.58(\mathrm{~m}$, $1 \mathrm{H}), 7.56-7.44(\mathrm{~m}, 2 \mathrm{H}), 7.42-7.11(\mathrm{~m}, 2 \mathrm{H}), 6.15-5.6(\mathrm{~m}, 1 \mathrm{H}), 5.00(\mathrm{~m}, 2 \mathrm{H}), 4.0-4.50(\mathrm{~m}, 1 \mathrm{H}), 3.91-$ $3.79(\mathrm{~m}, 3 \mathrm{H}), 3.40-2.50-3.4(\mathrm{~m}, 2 \mathrm{H}), 2.04-1.17(\mathrm{~m}, 7 \mathrm{H})$ (rotamers); LCMS (ESI): found [M+H] ${ }^{+}, 438.3$

\section{(R)-2-((4-benzoic acid)phenoxy)-1-(2-(4-(pyridin-2-yl)thiazol-2-yl)piperidin-1-yl)ethan-1-one (6n)}<smiles>O=C(O)c1ccc(OCC(=O)N2CCCCC2c2nc(-c3ccccn3)cs2)cc1</smiles>

Compound synthesized as per method $\mathrm{C}$, white solid with $43 \mathrm{mg}, 88 \%$ yield. ${ }^{1} \mathrm{H} \mathrm{NMR}(400 \mathrm{MHz}$, $\left.\mathrm{CD}_{3} \mathrm{OD}\right) \delta$ ppm 9.30-9.01 (m, $\left.1 \mathrm{H}\right)$, 8.85-8.49 (m, $\left.2 \mathrm{H}\right)$, 8.28-8.05 (m, $\left.1 \mathrm{H}\right)$, 7.90-7.61 $(\mathrm{m}, 3 \mathrm{H}), 7.10-$ $6.73(\mathrm{~m}, 2 \mathrm{H}), 6.13-5.51(\mathrm{~m}, 1 \mathrm{H}), 5.00(\mathrm{~m}, 2 \mathrm{H}), 4.54-3.77(\mathrm{~m}, 1 \mathrm{H}), 3.45-2.72(\mathrm{~m}, 1 \mathrm{H}), 2.64-1.32(\mathrm{~m}$, $7 \mathrm{H}$ ) (rotamers); LCMS (ESI): found $[\mathrm{M}+\mathrm{H}]^{+}, 424.3$

(R)-2-((3-benzoic acid)phenoxy)-1-(2-(4-(pyridin-2-yl)thiazol-2-yl)piperidin-1-yl)ethan-1-one (6o)<smiles>O=C(O)c1cccc(OCC(=O)N2CCCCC2c2nc(-c3ccccn3)cs2)c1</smiles>

Compound synthesized as per method $\mathrm{C}$, white solid with $35 \mathrm{mg}, 72 \%$ yield. ${ }^{1} \mathrm{H}$ NMR $(400 \mathrm{MHz}$, $\left.\mathrm{CD}_{3} \mathrm{OD}\right) \delta$ ppm 9.23-8.99 (m, $\left.1 \mathrm{H}\right), 8.64-8.43(\mathrm{~m}, 1 \mathrm{H}), 8.43-8.20(\mathrm{~m}, 1 \mathrm{H}), 8.06-7.99(\mathrm{~m}, 1 \mathrm{H}), 7.95-$ $7.81(\mathrm{~m}, 1 \mathrm{H}), 7.87-7.69(\mathrm{~m}, 1 \mathrm{H}), 7.67-7.59(\mathrm{~m}, 1 \mathrm{H}), 7.58-7.43(\mathrm{~m}, 3 \mathrm{H}), 7.43-7.12(\mathrm{~m}, 2 \mathrm{H}), 6.20-$ $5.51(\mathrm{~m}, 1 \mathrm{H}), 5.00(\mathrm{~m}, 2 \mathrm{H}), 4.60-3.90(\mathrm{~m}, 1 \mathrm{H}), 3.45-2.60(\mathrm{~m}, 1 \mathrm{H}), 1.86-0.79-(\mathrm{m}, 8 \mathrm{H})$ (rotamers); LCMS (ESI): found $[\mathrm{M}+\mathrm{H}]^{+}, 424.3$

\section{General procedure for compounds 9(a-c): Method D}

Under nitrogen atmosphere, dry DCM $(7.5 \mathrm{~mL})$ was added to a flask containing methyl 3aminobenzoate $(0.200 \mathrm{~g}, 1.3 \mathrm{mmol})$, then pyridine $(0.41 \mathrm{~mL}, 5.1 \mathrm{mmol})$ was added. 3,4dichlorobenzenesulfonyl chloride $(0.16 \mathrm{~mL}, 1.0 \mathrm{mmol})$ was added dropwise, then the solution was stirred for $3 \mathrm{~h}$ at RT. The mixture was poured into excess water and extracted with DCM. The organic layers were combined, washed with aqueous $1 \mathrm{~N} \mathrm{HCl}$, dried with $\mathrm{Na}_{2} \mathrm{SO}_{4}$, and concentrated in vacuo. The resulting residue was purified by silica gel chromatography with hexane/ethyl acetate combinations as eluent, giving rise to methyl 3-((3,4-dichlorophenyl)sulfonamido)benzoate $(0.262 \mathrm{~g})$ in $71 \%$ yield. $\mathrm{MS}(\mathrm{ESI})$ : found $[\mathrm{M}+\mathrm{H}]^{+}, 360.1$. This material was dissolved in methanol/water $(1 / 1 \mathrm{v} / \mathrm{v})$ and three equivalents of $\mathrm{LiOH}$ were added and the solution was stirred until the methyl ester was fully 
hydrolyzed. The majority of methanol was removed in vacuo and the resulting solution was extracted with EtOAc, dried with $\mathrm{Na}_{2} \mathrm{SO}_{4}$, and concentrated in vacuo, giving rise to 3-((3,4dichlorophenyl)sulfonamido)benzoic acid $\mathbf{9 a}$.

\section{3-((3,4-dichlorophenyl)sulfonamido)benzoic acid (9a)}<smiles>O=C(O)c1cccc(NS(=O)(=O)c2ccc(Cl)c(Cl)c2)c1</smiles>

Compound synthesized as per method D, white solid with $189 \mathrm{mg}$ in $75 \%$ yield; ${ }^{1} \mathrm{H}$ NMR $(400 \mathrm{MHz}$, $\left.\mathrm{CDCl}_{3}\right) \delta \mathrm{ppm}$ 7.85-7.79 (m, 1H), 7.75-7.69 (m, 2H), $7.42(\mathrm{~d}, J=8.61 \mathrm{~Hz}, 2 \mathrm{H}), 7.40-7.34(\mathrm{~m}, 1 \mathrm{H})$, $7.03(\mathrm{~s}, 1 \mathrm{H})$; LCMS (ESI): found $[\mathrm{M}+\mathrm{H}]^{+}$, 346.2.

\section{3-((4-chlorophenyl)sulfonamido)benzoic acid (9b)}<smiles>CC(=O)c1cccc(NS(=O)(=O)c2ccc(Cl)cc2)c1</smiles>

Compound synthesized as per method D, white solid with $155 \mathrm{mg}$ in $80 \%$ yield; ${ }^{1} \mathrm{H}$ NMR $(400 \mathrm{MHz}$, $\left.\mathrm{CDCl}_{3}\right) \delta \mathrm{ppm}$ 7.86-7.78 (m, 1H), 7.75-7.65 (m, 3H), $7.42(\mathrm{~d}, J=8.61 \mathrm{~Hz}, 2 \mathrm{H}), 7.39-7.35(\mathrm{~m}, 1 \mathrm{H})$, $7.02(\mathrm{~s}, 1 \mathrm{H})$; LCMS (ESI): found [M + Na] ${ }^{+}, 334.2$.

\section{3-((5-chloro-2-methoxyphenyl)sulfonamido)benzoic acid (9c)}<smiles>COc1ccc(Cl)cc1S(=O)(=O)Nc1cccc(C(=O)O)c1</smiles>

Compound synthesized as per method $\mathrm{D}$, white solid with $125 \mathrm{mg}$ in $77 \%$ yield; ${ }^{1} \mathrm{H}$ NMR $(400 \mathrm{MHz}$, $\left.\mathrm{CDCl}_{3}\right) \delta \mathrm{ppm} 7.81(\mathrm{~d}, J=2.74 \mathrm{~Hz}, 1 \mathrm{H}), 7.77(\mathrm{~d}, J=7.43 \mathrm{~Hz}, 1 \mathrm{H}), 7.66(\mathrm{~s}, 1 \mathrm{H}), 7.38-7.47(\mathrm{~m}, 2 \mathrm{H})$, 7.30-7.36 (m, 1H), $7.21(\mathrm{~s}, 1 \mathrm{H}), 6.95(\mathrm{~d}, J=8.61 \mathrm{~Hz}, 1 \mathrm{H}), 3.90(\mathrm{~s}, 3 \mathrm{H})$; LCMS (ESI): found [M + Na] ${ }^{+}$, 364.2 .

\section{General procedure for compounds 10(a-c): Method E}

Under nitrogen atmosphere, anhydrous THF $(3 \mathrm{~mL})$ was added to a flask containing $9 \mathrm{a}(0.130 \mathrm{~g}, 0.38$ $\mathrm{mmol})$ and the mixture was stirred in an ice/brine bath for $20 \mathrm{~min}$, then 4-methylmorpholine $(0.04 \mathrm{~mL}$, $0.38 \mathrm{mmol}$ ) and isopropyl chloroformate $(1.0 \mathrm{M}$ in THF, $0.38 \mathrm{~mL}$ ) were added and the solution was stirred an additional $10 \mathrm{~min}$. Anhydrous DMF $(1.5 \mathrm{~mL})$ containing methyl 4-aminobenzoate $(0.057 \mathrm{~g}$, $0.38 \mathrm{mmol}$ ) was added and the mixture was stirred in an ice/brine bath for $45 \mathrm{~min}$, then removed and allowed to warm to RT while being stirred over another $2 \mathrm{~h}$. The mixture was heated to $50^{\circ} \mathrm{C}$ overnight, then cooled and concentrated in vacuo. Excess water was added and the mixture was extracted with EtOAc $(2 \times 5 \mathrm{~mL})$, combined dried ethyl acetate dried over anhydrous $\mathrm{Na}_{2} \mathrm{SO}_{4}$, and concentrated in vacuo. The resulting residue was purified by silica gel chromatography with hexane/ethyl acetate combinations as eluent, giving rise to methyl 4-(3-((3,4dichlorophenyl)sulfonamido)benzamido)benzoate $(0.082 \mathrm{~g})$ in $46 \%$ yield. $M S(E S I)$ : found $[\mathrm{M}+\mathrm{H}]^{+}$, 479.2. This material was dissolved in methanol/water $(1 / 1 \mathrm{v} / \mathrm{v})$ and $\mathrm{LiOH}(3.0 \mathrm{eq})$ were added and the solution was stirred until the methyl ester was fully hydrolyzed. The majority of methanol was removed in vacuo and the resulting solution $\mathrm{pH} \sim 3$ was adjusted with $3 \mathrm{~N}$ aq. $\mathrm{HCl}$ and product was extracted with EtOAc $(2 \times 5 \mathrm{~mL})$, combined ethyl acetate washed with brine and dried over anhydrous $\mathrm{Na}_{2} \mathrm{SO}_{4}$, and concentrated in vacuo, then purified by HPLC (C18, 15*150 mm column; eluent: acetonitrile/water $(0.05 \%$ TFA)), giving rise to the title compound $10 \mathrm{a}$. 


\section{4-(3-((3,4-dichlorophenyl)sulfonamido)benzamido)benzoic acid (10a)}<smiles>O=C(O)c1ccc(NC(=O)c2cccc(NS(=O)(=O)c3ccc(Cl)c(Cl)c3)c2)cc1</smiles>

Compound synthesized as per method E, white solid with $15 \mathrm{mg}$ in $19 \%$ yield; ${ }^{1} \mathrm{H}$ NMR $(400 \mathrm{MHz}$, $\left.\mathrm{CD}_{3} \mathrm{OD}\right) \delta \mathrm{ppm}$ 8.03-8.01 (m, $\left.1 \mathrm{H}\right), 8.01-7.98(\mathrm{~m}, 1 \mathrm{H}), 7.88(\mathrm{~d}, J=2.0 \mathrm{~Hz}, 1 \mathrm{H}), 7.79-7.77(\mathrm{~m}, 1 \mathrm{H})$, 7.77-7.74 (m, $1 \mathrm{H}), 7-67-7.63(\mathrm{~m}, 2 \mathrm{H}), 7-62-7.60(\mathrm{~m}, 2 \mathrm{H}), 7-57-7.53(\mathrm{~m}, 2 \mathrm{H}), 7.41-7.36(\mathrm{~m}, 1 \mathrm{H})$, 7.36-7.31 (m, $1 \mathrm{H})$; LCMS (ESI): found [M + Na] ${ }^{+}, 467.1$.

\section{4-(3-((4-chlorophenyl)sulfonamido)benzamido)benzoic acid (10b)}<smiles>O=C(O)c1ccc(NC(=O)c2cccc(NS(=O)(=O)c3ccc(Cl)cc3)c2)cc1</smiles>

Compound synthesized as per method $\mathrm{E}$, white solid with $30 \mathrm{~g}$ in $67 \%$ yield; ${ }^{1} \mathrm{H} \mathrm{NMR}(400 \mathrm{MHz}$, $\left.\mathrm{CD}_{3} \mathrm{OD}\right) \delta \mathrm{ppm}$ 8.036-7.97 (m, $\left.2 \mathrm{H}\right), 7.78-7.66(\mathrm{~m}, 6 \mathrm{H})$, 7.65-7.59 (m, $\left.1 \mathrm{H}\right), 7.57-7.52(\mathrm{~m}, 1 \mathrm{H}), 7.48-$ $7.43(\mathrm{~m}, 1 \mathrm{H}), 7.43-7.37(\mathrm{~m}, 3 \mathrm{H}), 7.36-7.28(\mathrm{~m}, 3 \mathrm{H})$; LCMS (ESI): found $[\mathrm{M}+\mathrm{H}]^{+}, 431.3$.

\section{4-(3-((3-chlorophenyl)sulfonamido)benzamido)benzoic acid (10c)}<smiles>COc1ccc(Cl)cc1S(=O)(=O)Nc1cccc(C(=O)Nc2ccc(C(=O)O)cc2)c1</smiles>

Compound synthesized as per method E, white solid with $20 \mathrm{mg}$ in $61 \%$ yield; ${ }^{1} \mathrm{H}$ NMR $(400 \mathrm{MHz}$, $\left.\mathrm{CD}_{3} \mathrm{OD}\right) \delta \mathrm{ppm}$; 8.03-7.98 (m, $\left.2 \mathrm{H}\right), 7.82-7.78(\mathrm{~m}, 2 \mathrm{H}), 7.76(\mathrm{~d}, \mathrm{~J}=2.7 \mathrm{~Hz}, 1 \mathrm{H}), 7-68-7.65(\mathrm{~m}, 1 \mathrm{H})$, 7.59 (ddd, $J=5.6,3.2,1.8 \mathrm{~Hz}, 1 \mathrm{H}$ ), 7.49 (dd, $J=9.0,2.7 \mathrm{~Hz}, 1 \mathrm{H}), 7.39-7.35(\mathrm{~m}, 2 \mathrm{H}), 7.12(\mathrm{~d}, J=$ $9.0 \mathrm{~Hz}, 1 \mathrm{H}), 3.95(\mathrm{~s}, 3 \mathrm{H})$; LCMS (ESI): found [M + H] ${ }^{+}, 461.2$.

\section{General procedure for compounds 14(a-b): Method F}

Under nitrogen atmosphere, dry DCM (5 mL) was added to a flask containing methyl indoline-6carboxylate $11 \mathrm{a}(0.150 \mathrm{~g}, 0.8 \mathrm{mmol})$, then pyridine $(0.28 \mathrm{~mL}, 3.5 \mathrm{mmol})$ was added. 5-chloro-2methoxybenzenesulfonyl chloride $(0.170 \mathrm{~g}, 0.7 \mathrm{mmol})$ was dissolved in dry DCM $(5 \mathrm{~mL})$, which was added drop wise to the flask, then the solution was stirred for $8 \mathrm{~h}$ at RT. The mixture was poured into excess water and extracted with DCM. The organic layers were combined, washed with aqueous $1 \mathrm{~N}$ $\mathrm{HCl}$, dried with $\mathrm{Na}_{2} \mathrm{SO}_{4}$, and concentrated in vacuo. The resulting residue was purified by silica gel chromatography with hexane/ethyl acetate combinations as eluent, giving rise to methyl 1-((5-chloro2-methoxyphenyl)sulfonyl)indoline-6-carboxylate $13 \mathrm{a}(0.159 \mathrm{~g})$ in $60 \%$ yield. MS (ESI): found [M + $\mathrm{H}]^{+}$, 382.2. This material was dissolved in methanol/water $(1 / 1 \mathrm{v} / \mathrm{v})$ and three equivalents of $\mathrm{LiOH}$ were added and the solution was stirred until the methyl ester was fully hydrolyzed. The majority of methanol was removed in vacuo and the resulting solution was extracted with EtOAc, dried with $\mathrm{Na}_{2} \mathrm{SO}_{4}$, and concentrated in vacuo, giving rise to $14 \mathrm{a}$.

\section{1-((5-chloro-2-methoxyphenyl)sulfonyl)indoline-6-carboxylic acid (14a).}




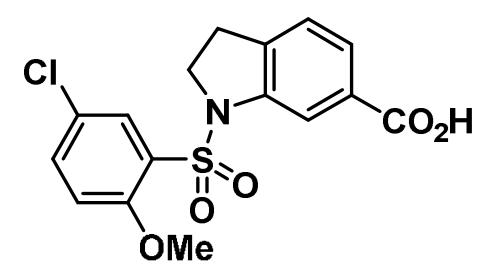

Compound synthesized as per method $\mathrm{F}$, white solid with $124 \mathrm{mg}$ in $81 \% ;{ }^{1} \mathrm{H} \mathrm{NMR}\left(400 \mathrm{MHz}^{\mathrm{CDCl}} \mathrm{CD}_{3}\right)$ $\delta$ ppm 8.07-8.04 (m, 1H), $8.01(\mathrm{~s}, 1 \mathrm{H}), 7.68(\mathrm{~d}, \mathrm{~J}=7.83 \mathrm{~Hz}, 1 \mathrm{H}), 7.47-7.42(\mathrm{~m}, 1 \mathrm{H}), 7.18(\mathrm{~d}, \mathrm{~J}=7.83$ $\mathrm{Hz}, 1 \mathrm{H}), 6.85(\mathrm{~d}, J=8.61 \mathrm{~Hz}, 1 \mathrm{H}), 4.11(\mathrm{t}, J=8.61 \mathrm{~Hz}, 2 \mathrm{H}), 3.63(\mathrm{~s}, 3 \mathrm{H}), 3.10(\mathrm{t}, J=8.61 \mathrm{~Hz}, 2 \mathrm{H})$; LCMS (ESI): found [M + Na] $]^{+}, 390.2$.

4-(3-((5-chloro-2-methoxyphenyl)sulfonamido)benzamido)benzoic acid (14b)<smiles>COc1ccc(C)cc1S(=O)(=O)N1CCCc2ccc(C(=O)O)cc21</smiles>

Compound synthesized as per method $\mathrm{F}$, white solid with $165 \mathrm{mg}$ in $83 \%$; ${ }^{1} \mathrm{H} \mathrm{NMR}\left(400 \mathrm{MHz}^{\mathrm{CDCl}} \mathrm{CD}_{3}\right)$ $\delta$ ppm 8.10-8.04 (m, 1H), $8.02(\mathrm{~s}, 1 \mathrm{H}), 7.70(\mathrm{~d}, J=7.81 \mathrm{~Hz}, 1 \mathrm{H}), 7.49-7.45(\mathrm{~m}, 1 \mathrm{H}), 7.20(\mathrm{~d}, J=7.84$ $\mathrm{Hz}, 1 \mathrm{H}), 6.85(\mathrm{~d}, J=8.62 \mathrm{~Hz}, 1 \mathrm{H}), 4.11(\mathrm{t}, J=8.61 \mathrm{~Hz}, 2 \mathrm{H}), 3.63(\mathrm{~s}, 3 \mathrm{H}), 3.10(\mathrm{t}, J=8.61 \mathrm{~Hz}, 2 \mathrm{H})$, $2.38(\mathrm{~s}, 3 \mathrm{H}), 2.00-1.96(\mathrm{~m}, 2 \mathrm{H})$; LCMS (ESI): found [M + Na] ${ }^{+}, 461.2$.

\section{General procedure for compounds 17(a-b): Method G}

Under nitrogen atmosphere, anhydrous THF (3 mL) was added to a flask containing 14a $(0.110 \mathrm{~g}$, $0.30 \mathrm{mmol}$ ) and the mixture was stirred in an ice/brine bath for $20 \mathrm{~min}$, then 4-methylmorpholine (0.03 $\mathrm{mL}, 0.30 \mathrm{mmol}$ ) and isopropyl chloroformate $(1.0 \mathrm{M}$ in THF, $0.30 \mathrm{~mL})$ were added to the and the solution was stirred an additional $10 \mathrm{~min}$. Anhydrous DMF (1 mL) containing methyl 4-aminobenzoate $(0.045 \mathrm{~g}, 0.30 \mathrm{mmol})$ was added and the mixture was stirred in an ice/brine bath for $45 \mathrm{~min}$., then removed and allowed to warm to $\mathrm{RT}$ while being stirred over another $30 \mathrm{~min}$. The mixture was heated to $60{ }^{\circ} \mathrm{C}$ for $4 \mathrm{~h}$, then cooled and concentrated in vacuo. Excess water was added and extracted with ethyl acetate $(10 \mathrm{~mL})$, dried over anhydrous $\mathrm{Na}_{2} \mathrm{SO}_{4}$, and concentrated in vacuo. The resulting residue was purified by silica gel chromatography with hexane/ethyl acetate combinations as eluent, giving rise to methyl 4-(1-((5-chloro-2-methoxyphenyl)sulfonyl)indoline-6-carboxamido)benzoate 16a $(0.060 \mathrm{~g})$ in $40 \%$ yield. This material was dissolved in methanol/water $(1 / 1 \mathrm{v} / \mathrm{v})$ and three equivalents of $\mathrm{LiOH}$ were added and the solution was stirred until the methyl ester was fully hydrolyzed. The majority of methanol was removed in vacuo and the resulting solution was extracted with EtOAc, dried with $\mathrm{Na}_{2} \mathrm{SO}_{4}$, and concentrated in vacuo, then purified by silica gel chromatography with methanol/dichloromethane combinations as eluent, giving rise to $45 \mathrm{mg}$ of the title compound $17 \mathrm{a}$.

4-(1-((5-chloro-2-methoxyphenyl)sulfonyl)indoline-6-carboxamido)benzoic acid (17a)<smiles>COc1ccc(Cl)cc1S(=O)(=O)N1CCc2ccc(C(=O)Nc3ccc(C(=O)O)cc3)cc21</smiles>

Compound synthesized as per method G, white solid with $45 \mathrm{mg}$ in $77 \%$ yield; ${ }^{1} \mathrm{H}$ NMR $(400 \mathrm{MHz}$, DMSO-d $)$ ) $\delta$ ppm 12.76 (br. s., $1 \mathrm{H}), 10.49$ (s, $1 \mathrm{H}), 7.95-7.89$ (m, $3 \mathrm{H}), 7.89-7.85$ (m, $1 \mathrm{H}), 7.73(\mathrm{~s}, 1$ H), 7.69 (dd, $J=9.0,2.7 \mathrm{~Hz}, 1 \mathrm{H}), 7.62(\mathrm{dd}, J=7.8,1.6 \mathrm{~Hz}, 1 \mathrm{H}), 7.36(\mathrm{~d}, J=7.8 \mathrm{~Hz}, 1 \mathrm{H}), 7.21(\mathrm{~d}, J=$ $9.0 \mathrm{~Hz}, 1 \mathrm{H}), 4.10(\mathrm{t}, J=8.6 \mathrm{~Hz}, 2 \mathrm{H}), 3.66(\mathrm{~s}, 3 \mathrm{H}), 3.19-3.08(\mathrm{~m}, 2 \mathrm{H})$; LCMS (ESI): found [M + H] ${ }^{+}$, 487.3. 
4-(1-((2-methoxy-6-methylphenyl)sulfonyl)-1,2,3,4-tetrahydroquinoline-7-carboxamido)benzoic acid (17b)<smiles>COc1ccc(C)cc1S(=O)(=O)N1CCCc2ccc(C(=O)Nc3ccc(CC(=O)O)cc3)cc21</smiles>

Compound synthesized as per method G, white solid with $69 \mathrm{mg}$ in $82 \%$ yield; ${ }^{1} \mathrm{H}$ NMR $(400 \mathrm{MHz}$, DMSO- $\left.d_{6}\right) \delta$ ppm $10.12(\mathrm{~s}, 1 \mathrm{H}), 8.02(\mathrm{~s}, 1 \mathrm{H}), 7.71(\mathrm{~s}, 1 \mathrm{H}), 7.67(\mathrm{~d}, J=8.6 \mathrm{~Hz}, 2 \mathrm{H}), 7.62-7.56(\mathrm{~m}, 1$ H), $7.42(\mathrm{~d}, J=6.7 \mathrm{~Hz}, 1 \mathrm{H}), 7.27-7.17(\mathrm{~m}, 3 \mathrm{H}), 7.05(\mathrm{~d}, J=8.6 \mathrm{~Hz}, 1 \mathrm{H}), 3.76(\mathrm{dd}, J=6.5,4.9 \mathrm{~Hz}, 2$ H), $3.55(\mathrm{~s}, 3 \mathrm{H}), 3.53(\mathrm{~s}, 2 \mathrm{H}), 2.73(\mathrm{t}, J=6.5 \mathrm{~Hz}, 2 \mathrm{H}), 2.29(\mathrm{~s}, 3 \mathrm{H}), 1.77-1.68(\mathrm{~m}, 2 \mathrm{H})$; LCMS (ESI): found $[\mathrm{M}+\mathrm{H}]^{+}, 495.4$.

\section{General procedure for compounds 23(a-c) and 24(a-c): Method H}

Aryl isocyanate 22a $(1.48 \mathrm{mmol})$ was added into a solution of methyl 4-(3-aminobenzamido)benzoate $21 \mathrm{a}^{46}(0.74 \mathrm{mmol})$ in DCM $(20 \mathrm{~mL})$ and the solution was stirred at room temperature and product slowly get precipitated from the solution, continued stirring for $24 \mathrm{~h}$. Filleted the product and washed with DCM $(5 \mathrm{~mL})$ and pure compounds $23(\mathrm{a}-\mathrm{c})$ were isolated.

$50 \%$ aq. $\mathrm{NaOH}$ solution $(2 \mathrm{~mL})$ was added into a solution of compounds $23 \mathrm{a}(100 \mathrm{mg}, 0.23 \mathrm{mmol})$ in methanol $(10 \mathrm{~mL})$ and stir the solution at room temperature for $24 \mathrm{~h}$. Progress of the reaction monitored by TLC and upon completion of the reaction, neutralized the reaction solution with $3 \mathrm{~N}$ aq. $\mathrm{HCl}$ under ice bath cooling and evaporated the solvent under reduced pressure. Diluted the crude mass with water $(10 \mathrm{~mL})$ and acidified the solution $(\mathrm{pH} \sim 2)$ by con. $\mathrm{HCl}$ under ice bath cooling, extracted product with Ethyl acetate $(3 \times 10 \mathrm{~mL})$ and washed the combined organic layer with brine $(10 \mathrm{~mL})$. Dried the Ethyl acetate layer over anhydrous $\mathrm{Na}_{2} \mathrm{SO}_{4}$ and evaporated the solvent under reduced pressure and pure compounds 24a.

methyl 4-(3-(3-(4-(dimethylamino)phenyl)ureido)benzamido)benzoate (23a)

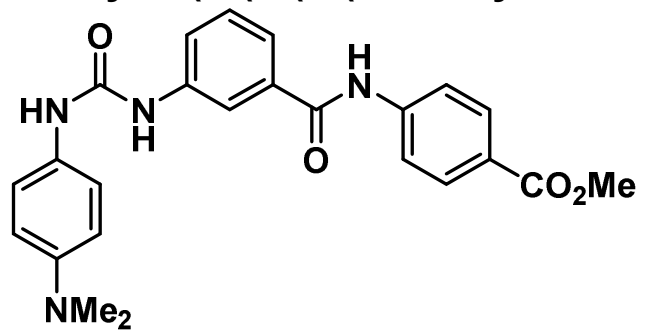

Compound synthesized as per method $\mathrm{H}$, off-white solid with $90 \mathrm{mg}$ in $56 \%$ yield; ${ }^{1} \mathrm{H} \mathrm{NMR}(400 \mathrm{MHz}$, DMSO- $\left.d_{6}\right) \delta$ ppm $10.56(\mathrm{~s}, 1 \mathrm{H}), 8.75(\mathrm{~s}, 1 \mathrm{H}), 8.35$ (s, $\left.1 \mathrm{H}\right), 7.95$ (br. s., $\left.5 \mathrm{H}\right), 7.67$ (d, J = $8.2 \mathrm{~Hz}, 1$ H), $7.53(\mathrm{~d}, J=7.4 \mathrm{~Hz}, 1 \mathrm{H}), 7.43(\mathrm{t}, J=7.8 \mathrm{~Hz}, 1 \mathrm{H}), 7.28(\mathrm{~s}, 2 \mathrm{H}), 6.70(\mathrm{~d}, J=9.0 \mathrm{~Hz}, 2 \mathrm{H}), 3.84(\mathrm{~s}, 3$ $\mathrm{H}), 2.83(\mathrm{~s}, 6 \mathrm{H}) ; \mathrm{LCMS}(\mathrm{ESI})$ : found $[\mathrm{M}+\mathrm{H}]^{+}, 433.3$.

methyl 4-(3-(3-(4-nitrophenyl)ureido)benzamido)benzoate (23b).<smiles>CC(=O)c1ccc(NC(=O)c2cccc(NC(=O)Nc3ccc([N+](=O)[O-])cc3)c2)cc1</smiles> 
Compound synthesized as per method $\mathrm{H}$, off-white solid with $200 \mathrm{mg}$ in $84 \%$ yield; ${ }^{1} \mathrm{H}$ NMR (400 $\left.\mathrm{MHz}, \mathrm{DMSO}-d_{6}\right) \delta \mathrm{ppm} 10.59(\mathrm{~s}, 1 \mathrm{H}), 9.50(\mathrm{~s}, 1 \mathrm{H}), 9.16(\mathrm{~s}, 1 \mathrm{H}), 8.20(\mathrm{~d}, J=9.0 \mathrm{~Hz}, 2 \mathrm{H}), 8.03(\mathrm{~s}, 1$ H), 7.90-8.00 (m, $5 \mathrm{H}), 7.72(\mathrm{~d}, J=9.0 \mathrm{~Hz}, 3 \mathrm{H}), 7.62(\mathrm{~d}, J=7.8 \mathrm{~Hz}, 1 \mathrm{H}), 7.49(\mathrm{t}, J=8.0 \mathrm{~Hz}, 1 \mathrm{H})$, $3.84(\mathrm{~s}, 3 \mathrm{H})$; LCMS (ESI): found $[\mathrm{M}+\mathrm{H}]^{+}$, 435.3.

methyl 4-(3-(3-(3,4-dichlorophenyl)ureido)benzamido)benzoate (AM1079-23c).<smiles>CC(=O)c1ccc(NC(=O)c2cccc(NC(=O)Nc3ccc(Cl)c(Cl)c3)c2)cc1</smiles>

Compound synthesized as per method $\mathrm{H}$, off-white solid with $120 \mathrm{mg}$ in $35 \%$ yield; ${ }^{1} \mathrm{H}$ NMR (400 $\left.\mathrm{MHz}, \mathrm{DMSO}-\mathrm{d}_{6}\right) \delta \mathrm{ppm} 10.58(\mathrm{~s}, 1 \mathrm{H}), 9.07(\mathrm{~s}, 2 \mathrm{H}), 8.03-7.86(\mathrm{~m}, 7 \mathrm{H}), 7.69(\mathrm{~d}, J=7.8 \mathrm{~Hz}, 1 \mathrm{H})$, $7.59(\mathrm{~d}, J=7.8 \mathrm{~Hz}, 1 \mathrm{H}), 7.53(\mathrm{~d}, J=8.6 \mathrm{~Hz}, 1 \mathrm{H}), 7.47(\mathrm{t}, J=7.8 \mathrm{~Hz}, 1 \mathrm{H}), 7.36(\mathrm{~d}, J=9.0 \mathrm{~Hz}, 1 \mathrm{H})$, $3.84(\mathrm{~s}, 3 \mathrm{H})$; LCMS (ESI): found [M + H] $]^{+}, 459.3$.

\section{4-(3-(3-(4-(dimethylamino)phenyl)ureido)benzamido)benzoic acid (24a)}<smiles>CN(C)c1ccc(NC(=O)Nc2cccc(C(=O)Nc3ccc(C(=O)O)cc3)c2)cc1</smiles>

Compound synthesized as per method $\mathrm{H}$, yellow solid with $10 \mathrm{mg}$ in $50 \%$ yield; ${ }^{1} \mathrm{H}$ NMR $(400 \mathrm{MHz}$, $\left.\mathrm{CD}_{3} \mathrm{OD}\right) \delta \mathrm{ppm}$ 8.07-7.99 (m, $\left.3 \mathrm{H}\right), 7.85(\mathrm{~d}, J=8.6 \mathrm{~Hz}, 2 \mathrm{H}), 7.68-7.58(\mathrm{~m}, 5 \mathrm{H}), 7.50-7.44(\mathrm{~m}, 1 \mathrm{H})$, 7.39 (br. s., $1 \mathrm{H}$ ), 3.20 (br. s., $6 \mathrm{H}$ ); LCMS (ESI): found $[\mathrm{M}+\mathrm{H}]^{+}, 419.3$.

4-(3-(3-(4-nitrophenyl)ureido)benzamido) benzoic acid (24b).<smiles>O=C(Nc1ccc(C(=O)O)cc1)Nc1cccc(C(=O)Nc2ccc([N+](=O)[O-])cc2)c1</smiles>

Compound synthesized as per method $\mathrm{H}$, white solid with $10 \mathrm{mg}$ in $50 \%$ yield; ${ }^{1} \mathrm{H}$ NMR $(400 \mathrm{MHz}$, $\left.\mathrm{CD}_{3} \mathrm{OD}\right) \delta \mathrm{ppm} 8.22(\mathrm{~m}, J=9.4 \mathrm{~Hz}, 2 \mathrm{H}), 8.06-8.00(\mathrm{~m}, 3 \mathrm{H}), 7.85(\mathrm{~m}, J=8.6 \mathrm{~Hz}, 2 \mathrm{H})$, 7.74-7.68 (m, $4 \mathrm{H}), 7.63(\mathrm{~d}, J=7.8 \mathrm{~Hz}, 1 \mathrm{H}), 7.49(\mathrm{t}, J=7.8 \mathrm{~Hz}, 1 \mathrm{H})$; LCMS (ESI): found $[M+\mathrm{H}]^{+}, 421.3$.

4-(3-(3-(3,4-dichlorophenyl)ureido)benzamido) benzoic acid (24c).<smiles>O=C(Nc1cccc(C(=O)Nc2ccc(C(=O)O)cc2)c1)Nc1ccc(Cl)c(Cl)c1</smiles> 
Compound synthesized as per method $\mathrm{H}$, white solid with $61 \mathrm{mg}$ in $77 \%$ yield; ${ }^{1} \mathrm{H} \mathrm{NMR}(400 \mathrm{MHz}$, $\left.\mathrm{CD}_{3} \mathrm{OD}\right) \delta$ ppm $10.54(\mathrm{~s}, 1 \mathrm{H}), 9.08(\mathrm{~d}, \mathrm{~J}=4.7 \mathrm{~Hz}, 2 \mathrm{H}), 8.06-7.85(\mathrm{~m}, 6 \mathrm{H}), 7.69(\mathrm{~d}, J=7.8 \mathrm{~Hz}, 1 \mathrm{H})$, $7.59(\mathrm{~d}, J=7.4 \mathrm{~Hz}, 1 \mathrm{H}), 7.53(\mathrm{~d}, J=8.6 \mathrm{~Hz}, 1 \mathrm{H}), 7.50-7.42(\mathrm{~m}, 1 \mathrm{H}), 7.36(\mathrm{~d}, J=9.0 \mathrm{~Hz}, 1 \mathrm{H})$; LCMS (ESI): found $[\mathrm{M}+\mathrm{Na}]^{+}, 445.3$.

\title{
ACKNOWLEDGMENTS
}

We thank Qi Wang for her technical assistance related to clustering compounds and identifying representatives for screening. This work was supported by National Institute of Allergy and Infectious Diseases (NIAID) grant Al081803 to M.M. The study was also partly supported by NIAID grant Al056189 to R.V.A.

\begin{abstract}
AUTHOR CONTRIBUTIONS
M.M. J.W.J., P.J.B., and R.A., conceived and designed the experiments. RT, J.J., and MM wrote the manuscript. A.R.M, R.C., and J.H, synthesized the compounds. C.F., C.A.B, J.S., M.E., performed in vitro and in vivo screening. M.Z., and J.H., performed the bioaccumulation assay. M.E, and C.A.B., prepared samples for the bioaccumulation assays. R.T., X.G., B.A.R., S.A.W., analyzed all the data. All authors edited the manuscript.
\end{abstract}

\section{Notes}

The authors declare no competing financial interest.

\section{ABBREVIATIONS USED}

CPT, carnitine palmitoyltransferase; MDA, mass drug administration; EC, Enzyme Commission number; PHX, perhexiline; STH, soil transmitted helminth; DMSO, dimethyl sylfoxide; SAR, structure activity relationships; PDB, Protein Databank; EDCI/EDC, 1-Ethyl-3-(3dimethylaminopropyl)carbodiimide; DIPEA, N,N-diisopropylethylamine; DMF, dimethylformamide; HPLC, high-performance liquid chromatography; LC-MS/LCMS, liquid chromatography-mass 
spectrometry; HEPES, 4-(2-hydroxyethyl)-1-piperazineethanesulfonic acid; MMU, mean movement unit; SDS, sodium dodecyl sulfate; TFA, trifluoroacetic acid; PBS, phosphate-buffered saline; iL3, infective L3 larval stage; p.i., post infection; NMR, nuclear magnetic resonance; TLC, thin layer chromatography; DCM, dichloromethane; DMAP, 4-Dimethylaminopyridine; RT, room temperature; CDI, 1,1'-Carbonyldiimidazole; HOBt, Hydroxybenzotriazole; EtOAc, Ethyl acetate.

\section{ASSOCIATED CONTENT}

\section{Supporting Information}

Figures S1-S45. Detailed information related to compound spectral data, general method and procedures, $1 \mathrm{H}-\mathrm{NMR} \& \mathrm{LCMS}$ spectral data for compounds $\mathbf{6 ( a - o )}, \mathbf{1 0}(\mathrm{a}-\mathrm{b}), \mathbf{1 7}(\mathrm{a}-\mathrm{b}), \mathbf{2 3}(\mathrm{a}-\mathrm{c})$ \& 24(ac) (Figure S1-S26). Time- and species- dependence of the $\mathrm{IC}_{50}$ values (Figure S27). Bioaccumulation assay data (Figure S28-S44). RNAseq based gene expression profiles (Figure S45). (PDF)

Tables S1-S6. Table S1. CPT orthologs based on orthoMCL of 16 nematode species, seven host species and two outgroups. Table S2. ChEMBL compounds linked to orthologous targets of nematode CPTs. Table S3. Selected available representatives drug-like compounds for screening in parasitic nematodes. Table S4. Results of the in vitro screening of various concentrations of the commercially available and synthesized compounds on multiple species of nematodes. Table S5. Amino acid variances in the nematode CPT2 sequences docking pocket (inferred based on the homology models). Number of amino acids diverse between reference (Rat CPT2; PDB id: 2FW3) and parasite CPT2 homolog within 5 and 10 Angstroms of the binding pocket. Table S6. Summary results of the bioaccumulation assay (all bioaccumulation analysis figures are available as Figure S28-S44). (XLSX) 


\section{REFERENCES}

1. Collaborators, G. D. a. I. I. a. P., Global, regional, and national incidence, prevalence, and years lived with disability for 310 diseases and injuries, 1990-2015: a systematic analysis for the Global Burden of Disease Study 2015. Lancet 2016, 388 (10053), 1545-1602. DOI: 10.1016/S01406736(16)31678-6.

2. Whitehead, A. G., Plant nematode control. . CAB: Wallingford, UK, 1998.

3. Mavrot, F.; Hertzberg, H.; Torgerson, P., Effect of gastro-intestinal nematode infection on sheep performance: a systematic review and meta-analysis. Parasit Vectors 2015, 8, 557. DOI: 10.1186/s13071-015-1164-z.

4. Molyneux, D. H.; Savioli, L.; Engels, D., Neglected tropical diseases: progress towards addressing the chronic pandemic. Lancet 2017, 389 (10066), 312-325. DOI: 10.1016/S01406736(16)30171-4.

5. McCarty, T. R.; Turkeltaub, J. A.; Hotez, P. J., Global progress towards eliminating gastrointestinal helminth infections. Curr Opin Gastroenterol 2014, 30 (1), 18-24. DOI: 10.1097/MOG.0000000000000025.

6. Helmy, H.; Weil, G. J.; Ellethy, A. S.; Ahmed, E. S.; Setouhy, M. E.; Ramzy, R. M., Bancroftian filariasis: effect of repeated treatment with diethylcarbamazine and albendazole on microfilaraemia, antigenaemia and antifilarial antibodies. Trans R Soc Trop Med Hyg 2006, 100 (7), 656-62. DOI: 10.1016/j.trstmh.2005.08.015.

7. Moulia-Pelat, J. P.; Glaziou, P.; Weil, G. J.; Nguyen, L. N.; Gaxotte, P.; Nicolas, L., Combination ivermectin plus diethylcarbamazine, a new effective tool for control of lymphatic filariasis. Trop Med Parasitol 1995, 46 (1), 9-12.

8. Kaplan, R. M.; Vidyashankar, A. N., An inconvenient truth: global worming and anthelmintic resistance. Veterinary parasitology 2012, 186 (1-2), 70-8. DOI: 10.1016/j.vetpar.2011.11.048.

9. Abongwa, M.; Marjanovic, D. S.; Tipton, J. G.; Zheng, F.; Martin, R. J.; Trailovic, S. M.; Robertson, A. P., Monepantel is a non-competitive antagonist of nicotinic acetylcholine receptors from 
Ascaris suum and Oesophagostomum dentatum. Int J Parasitol Drugs Drug Resist 2017, 8 (1), 36-42. DOI: 10.1016/j.ijpddr.2017.12.001.

10. Buxton, S. K.; Neveu, C.; Charvet, C. L.; Robertson, A. P.; Martin, R. J., On the mode of action of emodepside: slow effects on membrane potential and voltage-activated currents in Ascaris suum. Br J Pharmacol 2011, 164 (2b), 453-70. DOI: 10.1111/j.1476-5381.2011.01428.x.

11. Rufener, L.; Mäser, P.; Roditi, I.; Kaminsky, R., Haemonchus contortus acetylcholine receptors of the DEG-3 subfamily and their role in sensitivity to monepantel. PLoS Pathog 2009, 5 (4), e1000380. DOI: 10.1371/journal.ppat.1000380.

12. Taylor, C. M.; Wang, Q.; Rosa, B. A.; Huang, S. C.-C.; Powell, K.; Schedl, T.; Pearce, E. J.; Abubucker, S.; Mitreva, M., Discovery of Anthelmintic Drug Targets and Drugs Using Chokepoints in Nematode Metabolic Pathways. PLoS Pathog 2013, 9 (8), e1003505. DOI: 10.1371/journal.ppat.1003505.

13. Tyagi, R.; Rosa, B. A.; Lewis, W. G.; Mitreva, M., Pan-phylum Comparison of Nematode Metabolic Potential. PLoS Negl Trop Dis 2015, 9 (5), e0003788. DOI: 10.1371/journal.pntd.0003788.

14. Kim, T. Y.; Kim, H. U.; Lee, S. Y., Metabolite-centric approaches for the discovery of antibacterials using genome-scale metabolic networks. Metab Eng 2010, 12 (2), 105-11. DOI: 10.1016/j.ymben.2009.05.004.

15. Ceccarelli, S. M.; Chomienne, O.; Gubler, M.; Arduini, A., Carnitine palmitoyltransferase (CPT) modulators: a medicinal chemistry perspective on 35 years of research. $J$ Med Chem 2011, 54 (9), 3109-52. DOI: 10.1021/jm100809g.

16. Wagman, A. S.; Nuss, J. M., Current therapies and emerging targets for the treatment of diabetes. Curr Pharm Des 2001, 7 (6), 417-50.

17. Winchester, D. E.; Pepine, C. J., Angina treatments and prevention of cardiac events: an appraisal of the evidence. Eur Heart J Suppl 2015, 17 (Suppl G), G10-G18. DOI: 10.1093/eurheartj/suv054. 
18. Klug, D. M.; Gelb, M. H.; Pollastri, M. P., Repurposing strategies for tropical disease drug discovery. Bioorg Med Chem Lett 2016, 26 (11), 2569-76. DOI: 10.1016/j.bmcl.2016.03.103.

19. Wang, Q.; Heizer, E.; Rosa, B. A.; Wildman, S. A.; Janetka, J. W.; Mitreva, M., Characterization of parasite-specific indels and their proposed relevance for selective anthelminthic drug targeting. Infect Genet Evol 2016, 39, 201-211. DOI: 10.1016/j.meegid.2016.01.025.

20. Ashrafian, H.; Horowitz, J. D.; Frenneaux, M. P., Perhexiline. Cardiovasc Drug Rev 2007, 25 (1), 76-97. DOI: 10.1111/j.1527-3466.2007.00006.x.

21. Maggiora, G.; Vogt, M.; Stumpfe, D.; Bajorath, J., Molecular similarity in medicinal chemistry. J Med Chem 2014, 57 (8), 3186-204. DOI: 10.1021/jm401411z.

22. Lipinski, C. A., Lead- and drug-like compounds: the rule-of-five revolution. Drug Discov Today Technol 2004, 1 (4), 337-41. DOI: 10.1016/j.ddtec.2004.11.007.

23. Labonté, R.; Baum, F.; Sanders, D., Poverty, justice, and health. Oxford Textbook of Global Public Health 2015, 89.

24. Blaxter, M. L.; De Ley, P.; Garey, J. R.; Liu, L. X.; Scheldeman, P.; Vierstraete, A.; Vanfleteren, J. R.; Mackey, L. Y.; Dorris, M.; Frisse, L. M.; Vida, J. T.; Thomas, W. K., A molecular evolutionary framework for the phylum Nematoda. Nature 1998, 392 (6671), 71-5. DOI: 10.1038/32160.

25. Yin, X.; Dwyer, J.; Langley, S. R.; Mayr, U.; Xing, Q.; Drozdov, I.; Nabeebaccus, A.; Shah, A. M.; Madhu, B.; Griffiths, J.; Edwards, L. M.; Mayr, M., Effects of perhexiline-induced fuel switch on the cardiac proteome and metabolome. $J$ Mol Cell Cardiol 2013, 55, 27-30. DOI: 10.1016/j.yjmcc.2012.12.014.

26. Thupari, J. N.; Landree, L. E.; Ronnett, G. V.; Kuhajda, F. P., C75 increases peripheral energy utilization and fatty acid oxidation in diet-induced obesity. Proc Natl Acad Sci U S A 2002, 99 (14), 9498-502. DOI: 10.1073/pnas.132128899.

27. Bentebibel, A.; Sebastián, D.; Herrero, L.; López-Viñas, E.; Serra, D.; Asins, G.; GómezPuertas, P.; Hegardt, F. G., Novel effect of C75 on carnitine palmitoyltransferase I activity and palmitate oxidation. Biochemistry 2006, 45 (14), 4339-50. DOI: 10.1021/bi052186q. 
28. Tseng, C. C.; Noordali, H.; Sani, M.; Madhani, M.; Grant, D. M.; Frenneaux, M. P.; Zanda, M.;

Greig, I. R., Development of Fluorinated Analogues of Perhexiline with Improved Pharmacokinetic Properties and Retained Efficacy. J Med Chem 2017, 60 (7), 2780-2789. DOI: 10.1021/acs.jmedchem.6b01592.

29. Gu, L.; Liu, H.; Gu, X.; Boots, C.; Moley, K. H.; Wang, Q., Metabolic control of oocyte development: linking maternal nutrition and reproductive outcomes. Cell Mol Life Sci 2015, 72 (2), 251-71. DOI: 10.1007/s00018-014-1739-4.

30. Pearce, E. J.; Huang, S. C., The metabolic control of schistosome egg production. Cell Microbiol 2015, 17 (6), 796-801. DOI: 10.1111/cmi.12444.

31. Rosa, B. A.; Jasmer, D. P.; Mitreva, M., Genome-wide tissue-specific gene expression, coexpression and regulation of co-expressed genes in adult nematode Ascaris suum. PLOS Negl Trop Dis 2014, 8 (2), e2678. DOI: 10.1371/journal.pntd.0002678.

32. Blaxter, M. L., Nematoda: genes, genomes and the evolution of parasitism. Adv Parasitol 2003, 54, 101-95.

33. Adoutte, A.; Balavoine, G.; Lartillot, N.; de Rosa, R., Animal evolution. The end of the intermediate taxa? Trends Genet 1999, 15 (3), 104-8.

34. Soukhathammavong, P. A.; Sayasone, S.; Phongluxa, K.; Xayaseng, V.; Utzinger, J.; Vounatsou, P.; Hatz, C.; Akkhavong, K.; Keiser, J.; Odermatt, P., Low efficacy of single-dose albendazole and mebendazole against hookworm and effect on concomitant helminth infection in Lao PDR. PLoS Negl Trop Dis 2012, 6 (1), e1417. DOI: 10.1371/journal.pntd.0001417.

35. Hu, Y.; Ellis, B. L.; Yiu, Y. Y.; Miller, M. M.; Urban, J. F.; Shi, L. Z.; Aroian, R. V., An extensive comparison of the effect of anthelmintic classes on diverse nematodes. PLoS One 2013, 8 (7), e70702. DOI: 10.1371/journal.pone.0070702.

36. Fischer, S.; Brunk, B. P.; Chen, F.; Gao, X.; Harb, O. S.; lodice, J. B.; Shanmugam, D.; Roos, D. S.; Stoeckert, C. J., Using OrthoMCL to assign proteins to OrthoMCL-DB groups or to cluster 
proteomes into new ortholog groups. Curr Protoc Bioinformatics 2011, Chapter 6, Unit 6.12.1-19. DOI: 10.1002/0471250953.bi0612s35.

37. Martin, J.; Rosa, B. A.; Ozersky, P.; Hallsworth-Pepin, K.; Zhang, X.; Bhonagiri-Palsikar, V.; Tyagi, R.; Wang, Q.; Choi, Y. J.; Gao, X.; McNulty, S. N.; Brindley, P. J.; Mitreva, M., Helminth.net: expansions to Nematode.net and an introduction to Trematode.net. Nucleic Acids Res 2015, 43 (Database issue), D698-706. DOI: 10.1093/nar/gku1128.

38. Guha, R.; Howard, M. T.; Hutchison, G. R.; Murray-Rust, P.; Rzepa, H.; Steinbeck, C.; Wegner, J.; Willighagen, E. L., The Blue Obelisk-interoperability in chemical informatics. J Chem Inf Model 2006, 46 (3), 991-8. DOI: 10.1021/ci050400b.

39. Irwin, J. J.; Shoichet, B. K., ZINC--a free database of commercially available compounds for virtual screening. J Chem Inf Model 2005, 45 (1), 177-82. DOI: 10.1021/ci049714+.

40. Rufer, A. C.; Thoma, R.; Benz, J.; Stihle, M.; Gsell, B.; De Roo, E.; Banner, D. W.; Mueller, F.; Chomienne, O.; Hennig, M., The crystal structure of carnitine palmitoyltransferase 2 and implications for diabetes treatment. Structure 2006, 14 (4), 713-23. DOI: 10.1016/j.str.2006.01.008.

41. Conti, R.; Mannucci, E.; Pessotto, P.; Tassoni, E.; Carminati, P.; Giannessi, F.; Arduini, A., Selective reversible inhibition of liver carnitine palmitoyl-transferase 1 by teglicar reduces gluconeogenesis and improves glucose homeostasis. Diabetes 2011, 60 (2), 644-51. DOI: $10.2337 / \mathrm{db} 10-0346$.

42. Case, D. A.; Darden, T.; Cheatham, T.; Simmerling, C. L.; Wang, J.; Duke, R. E.; Luo, R.; Crowley, M.; Walker, R. C.; Zhang, W. Amber 10; University of California: 2008.

43. Marcellino, C.; Gut, J.; Lim, K. C.; Singh, R.; McKerrow, J.; Sakanari, J., WormAssay: a novel computer application for whole-plate motion-based screening of macroscopic parasites. PLoS Negl Trop Dis 2012, 6 (1), e1494. DOI: 10.1371/journal.pntd.0001494.

44. Hu, Y.; Miller, M. M.; Derman, A. I.; Ellis, B. L.; Monnerat, R. G.; Pogliano, J.; Aroian, R. V., Bacillus subtilis strain engineered for treatment of soil-transmitted helminth diseases. Appl Environ Microbiol 2013, 79 (18), 5527-32. DOI: 10.1128/AEM.01854-13. 
45. a) Johns, B. A., Kawasuji, T.; Taishi, T.; Taoda, Y. (2006) Polycyclic carbamoylpyridone derivative having HIV integrase inhibitory activity and their preparation. PCT Int. Appl. WO 2006116764. b) Andjekovic, M.; Ceccarelli, S. M.; Chomienne, O.; Mattei, P. (2008) preparationof phenoxyacetylpiperidinylthiaziles as liver carnitine palmytoyl transferase (L-CPT1) inhibitors. U.S. Pat. Appl. Publ. US 20080300279.

46. Chen, Y.; Wen, D.; Huang, Z.; Huang, M.; Luo, Y.; Liu, B.; Lu, H.; Wu, Y.; Peng, Y.; Zhang, J., 2-(4-Chlorophenyl)-2-oxoethyl 4-benzamidobenzoate derivatives, a novel class of SENP1 inhibitors: Virtual screening, synthesis and biological evaluation. Bioorganic \& Medicinal Chemistry Letters 2012, $22(22), 6867-6870$. 


\section{FIGURE LEGENDS}

Figure 1. Overall workflow. (A) Identification of publicly available CPT-modulators: CPT orthologs in 23 species were identified and used to find CPT homologs in ChEMBL's target database. The 105 compounds targeting these CPT homologs in the ChEMBL database were grouped into nine clusters based on their structure and five representatives were prioritized for screening after filtering for druglikeness, commercial availability and cost. (B) Synthesizing known mammalian CPT-modulators. Four known CPT inhibitor compounds were synthesized and used in in vitro screening. Two of these were found to be deleterious to the worms, and were used for docking studies. Based on the docking results 22 analogs were synthesized and used for in vitro screening. (C) in vitro screening was accomplished for a total of 33 compounds in adult stage of multiple parasitic nematode species, of those 10 were hits in both intestinal and filarial nematodes.

Scheme 1. Synthesis of known mammalian small molecule CPT inhibitors and analogs. (A) Synthesis of known compound 6a and its newly designed analogs. (B) Synthesis of known compound $10 \mathrm{a}$ and its newly designed analogs.

Scheme 2. Synthesis of known CPT inhibitors $\mathbf{1 7 ( a - b )}$ as conformationally restricted sulfonamide analogs of $\mathbf{6 a}$.

Figure 2. In vitro screening in intestinal and filarial nematodes. (A) Compounds screened to identify their pan-phylum potential based on motility inhibition. For complete set of results and details on the molecular weight and tested concentrations see Table S4. Dose response assay data for 6a and its analogs $\mathbf{6 c}$ and $\mathbf{6 d}$ from in vitro screening of whipworm $(B)$ and filarial nematode $(C)$. This is a subset compiled from the full dataset to illustrate the most striking results. 
Figure 3. (A) Molecular docking of inhibitors bound to T. muris CPT2 (orange) based on rat CPT2 2FW3 (magenta). (B) Overlay of 6a (cyan), 10a (green) and 17a (yellow). Residues of CPT2 homology model in $T$. muris are in orange and rat CPT2 is in magenta. Targeted differences in the CoA binding site of T. muris are shown as sticks. (i) Thr (rat), Val (Tm); (i) Phe (rat), Tyr (Tm); (iii) Lys (rat), Arg (Tm); (iv) Asn (rat), Thr (Tm).

Figure 4. Rational design chemistry plan: (A) 6a and (B) 10a.

Scheme 3. Synthesis of compounds 24(a-c) as novel urea analogs of known CPT inhibitor 10a.

Figure 5. Perhexiline reduces fecal egg count but not total worm load. (A) Treatment with perhexiline significantly reduced fecal egg count in Syrian hamsters infected with the hookworm A. ceylanicum compared with untreated control animals. (B) The fecal egg count reduction was not accompanied by a reduction of worm load, which was not statistically significant between control and treated animals. (C) and (D) RNAseq based gene expression profile over developmental stages of $A$. ceylanicum shows increased expression of CPT1/2 in adult female compared to L4 female, L4 male and adult male. 


\section{For Table of Contents Use Only}

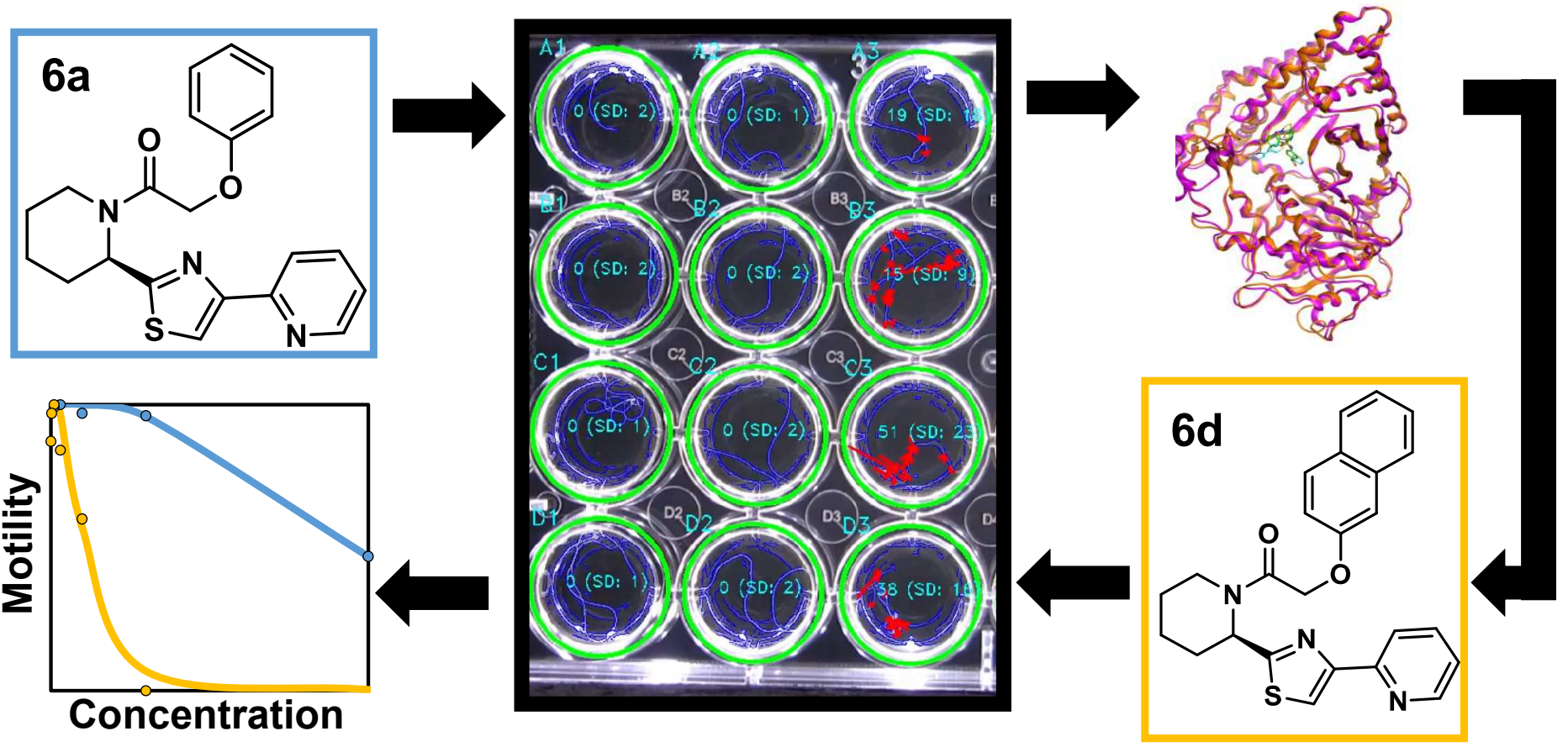


B. Synthesized compounds

A. Commercially available compounds

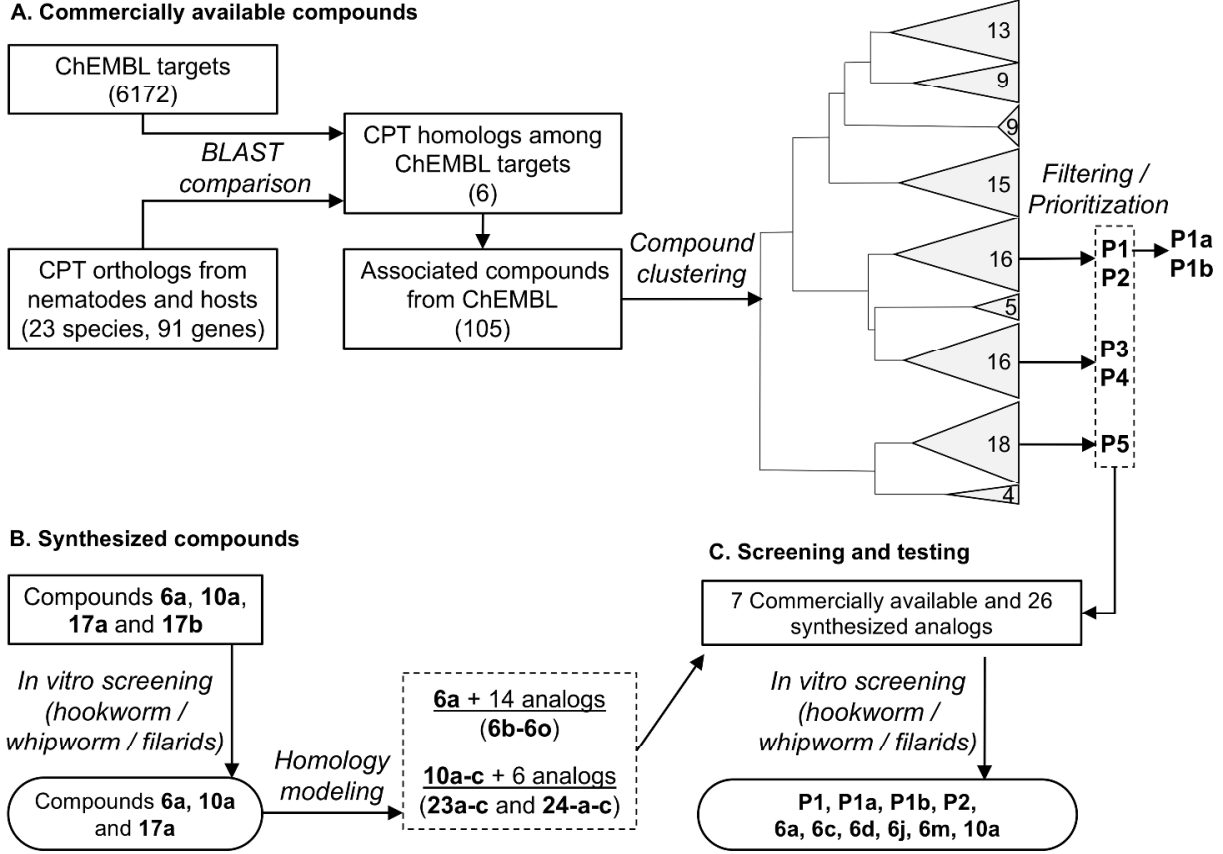

Figure 1. Overall workflow. (A) Identification of publicly available CPT-modulators: CPT orthologs in 23 species were identified and used to find CPT homologs in ChEMBL's target database. The 105 compounds targeting these CPT homologs in the ChEMBL database were grouped into nine clusters based on their structure and five representatives were prioritized for screening after filtering for drug-likeness, commercial availability and cost. (B) Synthesizing known mammalian CPT-modulators. Four known CPT inhibitor compounds were synthesized and used in in vitro screening. Two of these were found to be deleterious to the worms, and were used for docking studies. Based on the docking results 22 analogs were synthesized and used for in vitro screening. (C) in vitro screening was accomplished for a total of 33 compounds in adult stage of multiple parasitic nematode species, of those 10 were hits in both intestinal and filarial nematodes.

$304 \times 215 \mathrm{~mm}(300 \times 300 \mathrm{DPI})$ 
Scheme 1. Synthesis of known mammalian small molecule CPT inhibitors and analogs. (A) Synthesis of known compound $6 \mathrm{a}$ and its newly designed analogs. (B) Synthesis of known compound 10a and its newly designed analogs.

\section{$215 \times 151 \mathrm{~mm}(300 \times 300 \mathrm{DPI})$}

\section{Scheme 1. Synthesis of compounds $\mathbf{6}(\mathrm{a}-\mathrm{o}) \& \mathbf{1 0}(\mathrm{a}-\mathrm{c})$}

Scheme A. Synthesis of compounds 6(a-o)
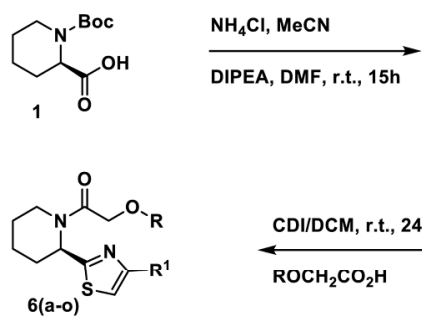

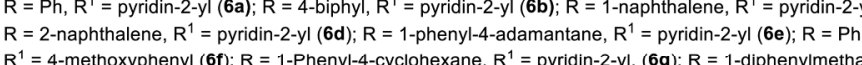$$
\mathrm{R}^{1}=\text { pyridin-2-yl }(6 \mathrm{~h}), \mathrm{R}=4 \text {-methyl-1, } 1^{\prime} \text {-biphenyl, } \mathrm{R}^{1}=\text { pyridin-2-yl }(\mathbf{6} \mathbf{i}) ; \mathrm{R}=2 \text {-phenylpyridine, } \mathrm{R}^{1}=\text { pyridin-2-yl }(\mathbf{6} \mathbf{j}) ;
$$$$
\mathrm{R}=\mathrm{Ph}, \mathrm{R}^{1}=\text { naphthalen-2-yl }(\mathbf{6 k}) ; \mathrm{R}=\mathrm{Ph}\left(4-\mathrm{CO}_{2} \mathrm{Me}\right), \mathrm{R}^{1}=\text { pyridin-2-yl }(6 \mathrm{l}) ; \mathrm{R}=\mathrm{Ph}\left(3-\mathrm{CO}_{2} \mathrm{Me}\right), \mathrm{R}^{1}=\text { pyridin-2-yl }(6 \mathrm{~m})
$$
$\mathrm{R}=\mathrm{Ph}\left(4-\mathrm{CO}_{2} \mathrm{H}\right), \mathrm{R}^{1}=$ pyridin-2-yl $(6 \mathrm{n}) ; \mathrm{R}=\mathrm{Ph}\left(3-\mathrm{CO}_{2} \mathrm{H}\right), \mathrm{R}^{1}=$ pyridin-2-yl $(60)$

Scheme B. Synthesis of compounds 10(a-c)

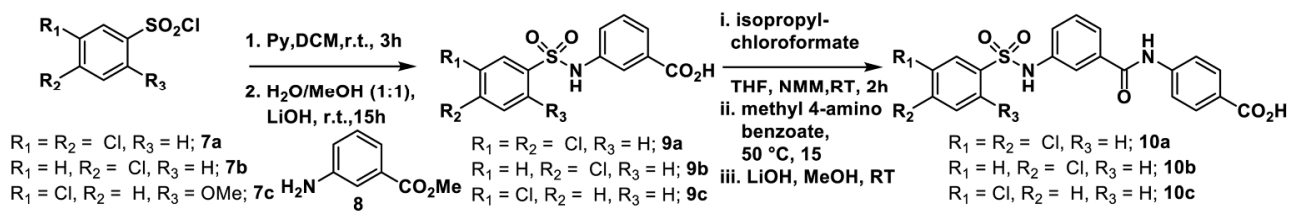




\section{Scheme 2. Synthesis of compounds $17(a-b)$}

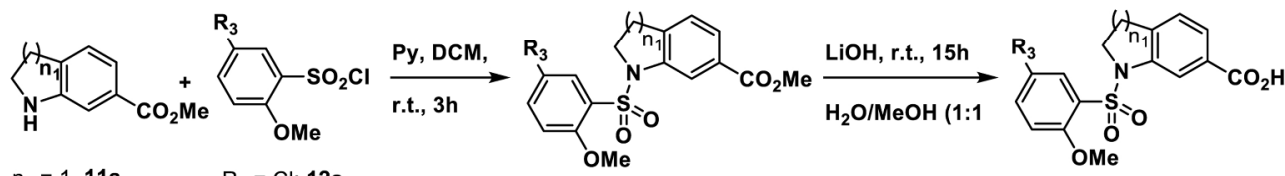

$n_{1}=1,11 a$

$\mathrm{R}_{3}=\mathrm{Cl} ; 12 \mathrm{a}$

$\mathrm{n}_{1}=2,11 \mathrm{~b} \quad \mathrm{R}_{3}=\mathrm{Me} ; \mathbf{1 2 b}$

$\mathrm{n}_{1}=1, \mathrm{R}_{3}=\mathrm{Cl} ; \mathbf{1 3 a}$

$\mathrm{n}_{1}=1, \mathrm{R}_{3}=\mathrm{Cl} ; \mathbf{1 4 a}$ $n_{1}=2, R_{3}=M e ; 13 b$
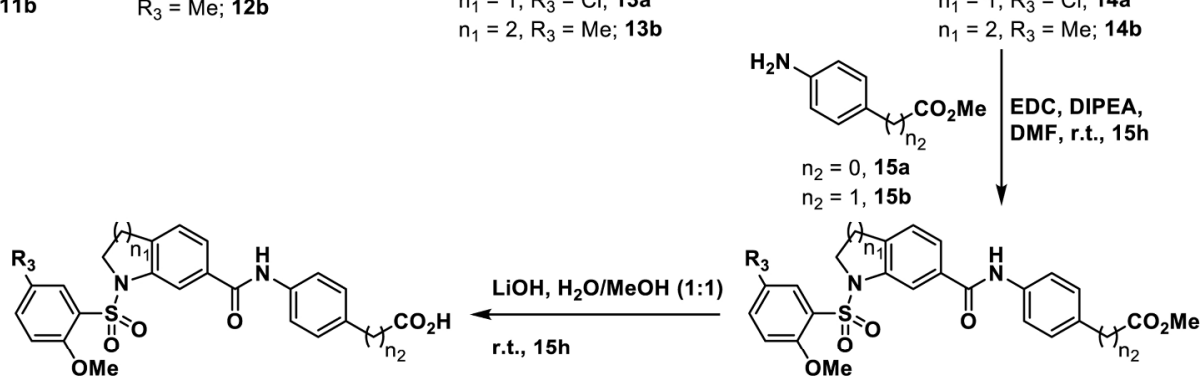

$\mathrm{n}_{1}=1, \mathrm{n}_{2}=0, \mathrm{R}_{3}=\mathrm{Cl} ; 17 \mathrm{a}$ $n_{1}=2, n_{2}=1, R_{3}=M e ; 17 b$

$\mathrm{n}_{1}=1, \mathrm{n}_{2}=0, \mathrm{R}_{3}=\mathrm{Cl} ; \mathbf{1 6 a}$ $n_{1}=2, n_{2}=1, R_{3}=M e ; 16 b$

Scheme 2. Synthesis of known CPT inhibitors $17(a-b)$ as conformationally restricted sulfonamide analogs of $6 a$.

$215 \times 126 \mathrm{~mm}(300 \times 300 \mathrm{DPI})$ 


\begin{tabular}{|c|c|c|c|c|c|c|c|c|}
\hline \multirow[b]{2}{*}{ Group } & \multirow[b]{2}{*}{$\begin{array}{c}\text { S. } \\
\text { No. }\end{array}$} & \multirow[b]{2}{*}{ Compound } & \multicolumn{5}{|c|}{ Motility Index } & \multirow{2}{*}{\begin{tabular}{|c|}
$\begin{array}{c}\text { Motility } \\
\text { inhibition (\%) }\end{array}$ \\
B. pahangi \\
$(100 \mu \mathrm{M})^{\star}$ \\
$72 \mathrm{hrs}$ \\
\end{tabular}} \\
\hline & & & $\begin{array}{c}\text { Tested } \\
\text { molarity } \\
(\mu \mathrm{M})^{\star}\end{array}$ & $\begin{array}{c}\mathrm{N} . \\
\text { brasiliensis } \\
48 \mathrm{hrs} \\
\end{array}$ & $\begin{array}{c}\mathrm{H} . \\
\text { polygyrus } \\
72 \mathrm{hrs} \\
\end{array}$ & $\begin{array}{c}A . \\
\text { ceylanicum } \\
24 \mathrm{hrs} \\
\end{array}$ & $\begin{array}{c}T . \\
\text { suis } \\
48 \mathrm{hrs}\end{array}$ & \\
\hline \multirow{5}{*}{$\begin{array}{l}\text { Commercially } \\
\text { available } \\
\text { inhibitors }\end{array}$} & P1 & Perhexiline malate salt & 203 & 0.00 & 0.00 & 0.00 & 0.00 & 100 \\
\hline & $\mathbf{P 2}$ & $\begin{array}{l}\text { (C75) 4-Methylene-2-octyl-5- } \\
\text { oxotetrahydrofuran-3-carboxylic acid }\end{array}$ & 315 & 2.37 & 18.3 & 1.90 & 0.00 & 95 \\
\hline & P3 & $\begin{array}{l}\text { sodium 2-(4-hydroxyphenyl)-2- } \\
\text { oxoacetate }\end{array}$ & 339 & 2.55 & 2.17 & 2.30 & 2.88 & 10 \\
\hline & P4 & $\begin{array}{l}\text { 1-[(2,3,4-trimethoxyphenyl) } \\
\text { methyl]piperazine dihydrochloride }\end{array}$ & 236 & 1.01 & 2.71 & 2.30 & 3.00 & 0 \\
\hline & P5 & Methyl 2-methylglycidate & 344 & 2.57 & 1.29 & 2.80 & 0.00 & 2 \\
\hline \multirow{4}{*}{$\begin{array}{c}\text { Synthesized } \\
\text { known } \\
\text { mamalian CPT } \\
\text { inhibitors }\end{array}$} & $6 a$ & $\mathrm{C}_{21} \mathrm{H}_{21} \mathrm{~N}_{3} \mathrm{O}_{2} \mathrm{~S}$ & 211 & 0.10 & 1.50 & 2.00 & 0.00 & 96 \\
\hline & 10a & $\mathrm{C}_{20} \mathrm{H}_{14} \mathrm{Cl}_{2} \mathrm{~N}_{2} \mathrm{O}_{5} \mathrm{~S}$ & 172 & 0.69 & 1.83 & 2.00 & 3.00 & 100 \\
\hline & $17 a$ & $\mathrm{C}_{23} \mathrm{H}_{19} \mathrm{CIN}_{2} \mathrm{O}_{6} \mathrm{~S}$ & 164 & 2.51 & 2.46 & 1.00 & 2.90 & 30 \\
\hline & $17 \mathrm{~b}$ & $\mathrm{C}_{26} \mathrm{H}_{26} \mathrm{~N}_{2} \mathrm{O}_{6} \mathrm{~S}$ & 162 & 2.10 & 2.67 & 2.00 & 3.00 & 0 \\
\hline
\end{tabular}

Motility Index code 3 High motility 2 Motile 1 Motile only when touched 0 No motility at all
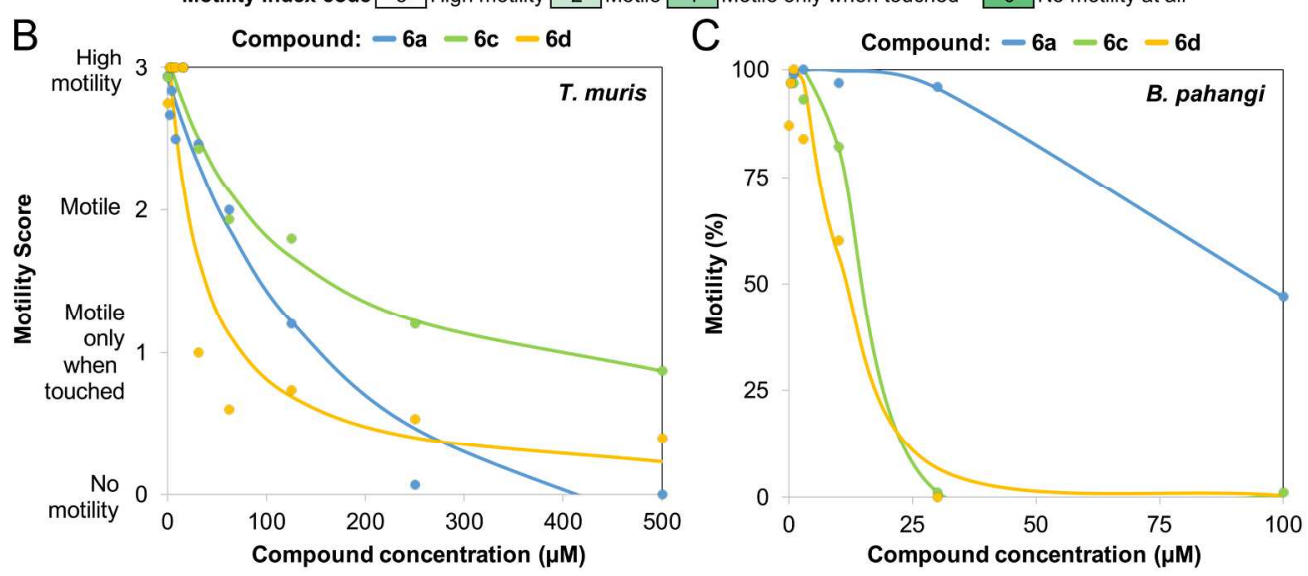

Figure 2. In vitro screening in intestinal and filarial nematodes. (A) Compounds screened to identify their pan-phylum potential based on motility inhibition. For complete set of results and details on the molecular weight and tested concentrations see Table S4. Dose response assay data for $6 \mathrm{a}$ and its analogs $6 \mathrm{c}$ and $6 \mathrm{~d}$ from in vitro screening of whipworm (B) and filarial nematode (C). This is a subset compiled from the full dataset to illustrate the most striking results.

$$
215 \times 212 \mathrm{~mm}(300 \times 300 \mathrm{DPI})
$$



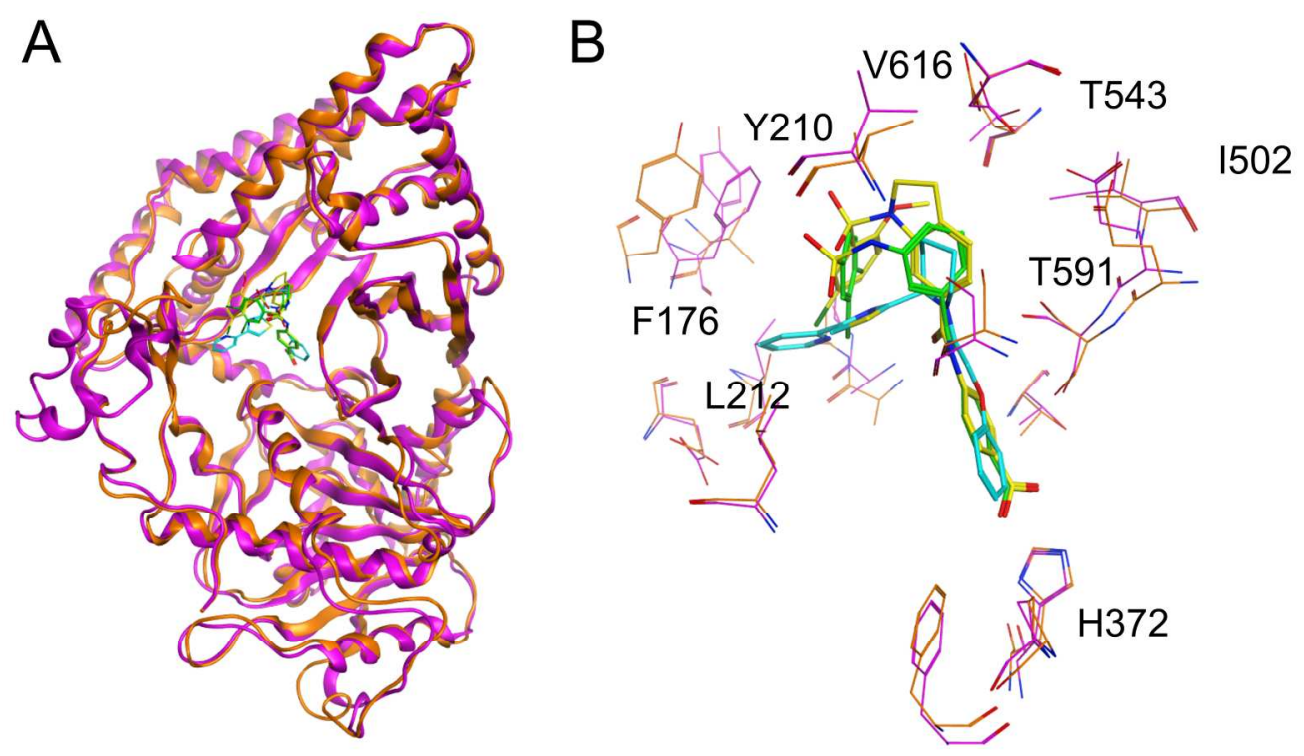

Figure 3. (A) Molecular docking of inhibitors bound to T. muris CPT2 (orange) based on rat CPT2 2 FW3 (magenta). (B) Overlay of 6a (cyan), 10a (green) and 17a (yellow). Residues of CPT2 homology model in T. muris are in orange and rat CPT2 is in magenta. Targeted differences in the CoA binding site of T. muris are shown as sticks. (i) Thr (rat), Val (Tm); (i) Phe (rat), Tyr (Tm); (iii) Lys (rat), Arg (Tm); (iv) Asn (rat), Thr (Tm).

$215 \times 127 \mathrm{~mm}(300 \times 300 \mathrm{DPI})$ 
A

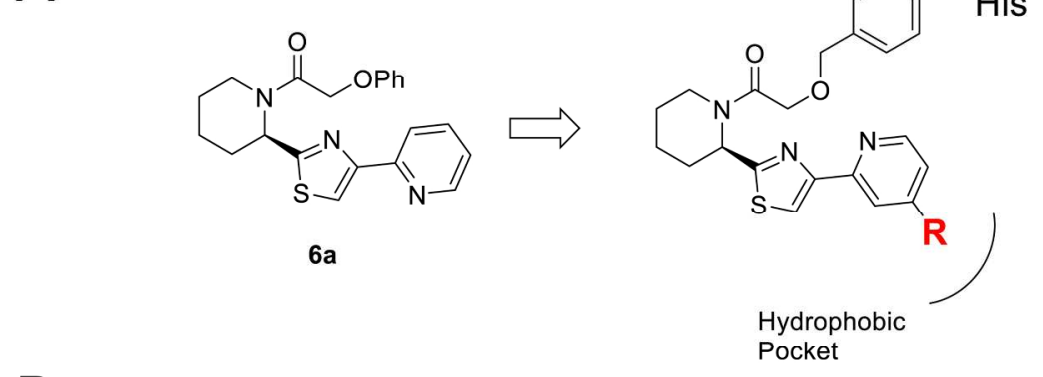

B
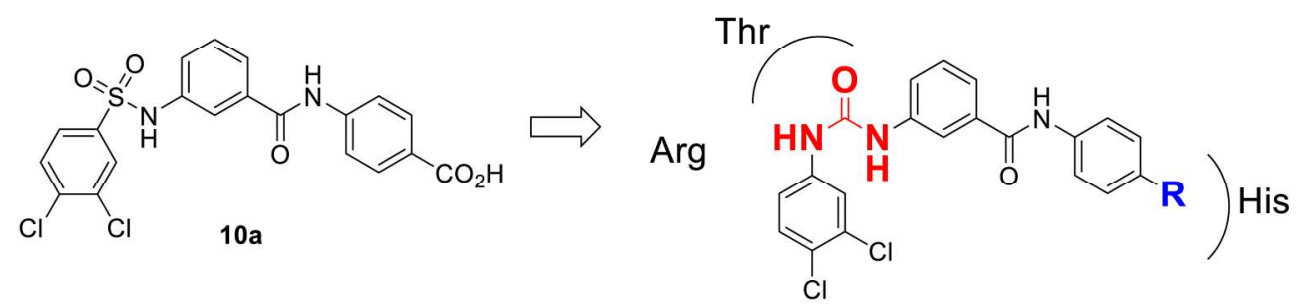

Figure 4. Rational design chemistry plan: (A) 6a and (B) 10a.

$215 \times 133 \mathrm{~mm}(300 \times 300 \mathrm{DPI})$ 
Scheme 3. Synthesis of compounds 24(a-c)

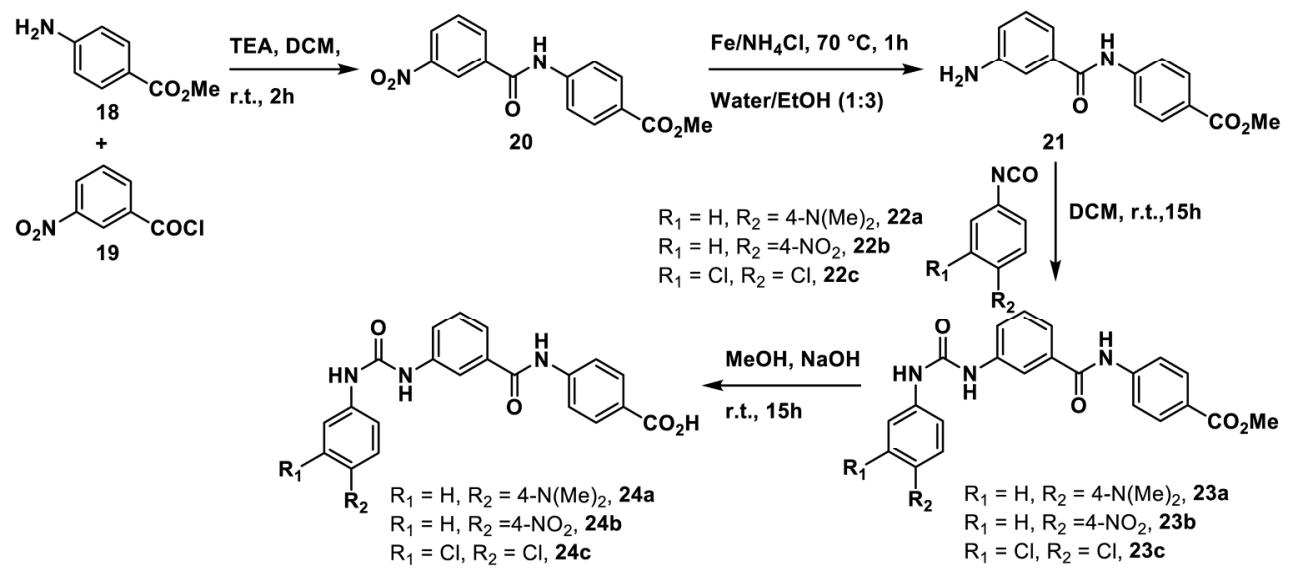

Scheme 3. Synthesis of compounds $24(\mathrm{a}-\mathrm{c})$ as novel urea analogs of known CPT inhibitor 10a.

$215 \times 106 \mathrm{~mm}(300 \times 300$ DPI $)$ 

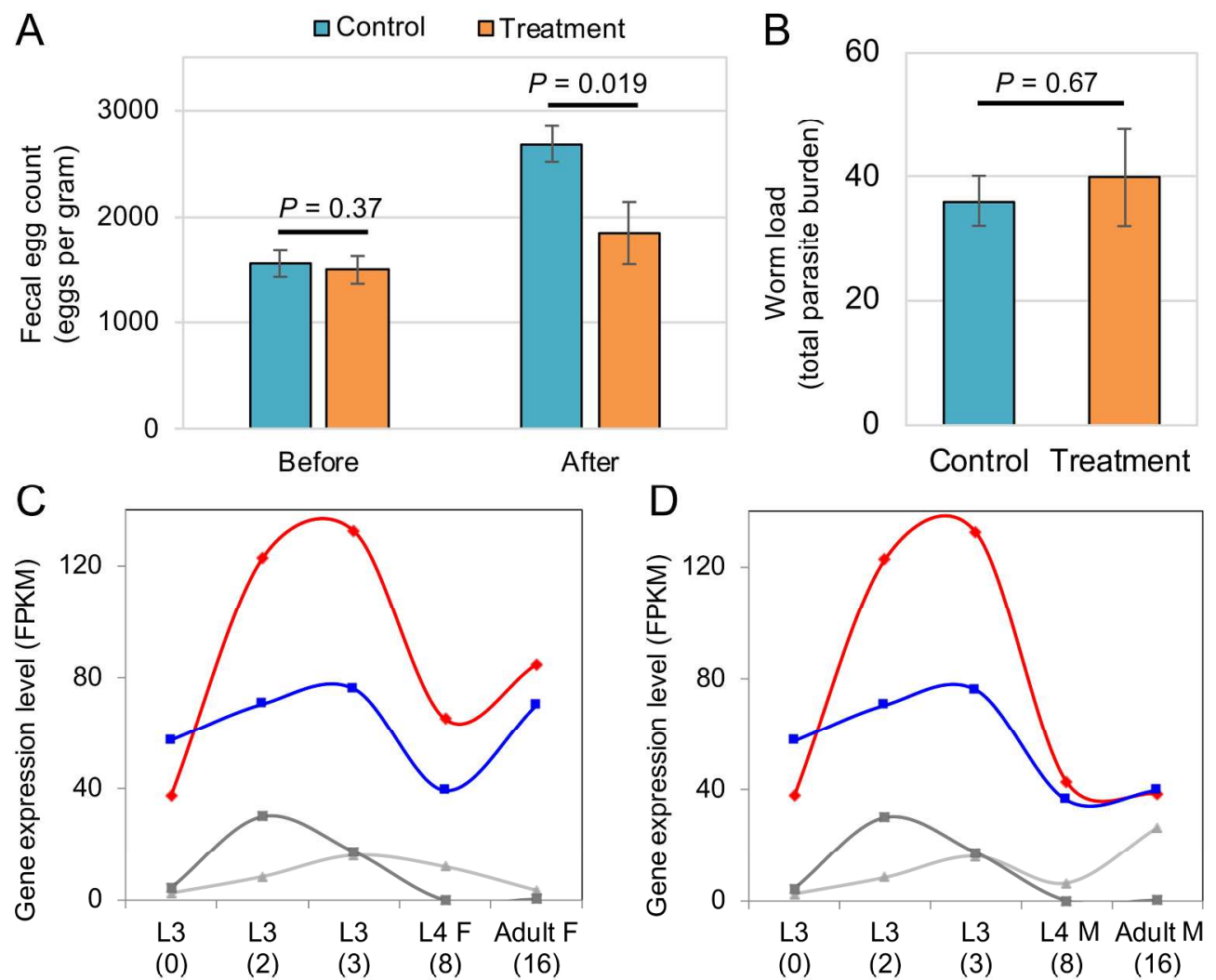

Life cycle stages (days post infection)

Life cycle stages (days post infection)

$\rightarrow$ CPT-1 $\rightarrow$-CPT-2 $=$ CPT-3 to 6

Figure 5. Perhexiline reduces fecal egg count but not total worm load. (A) Treatment with perhexiline significantly reduced fecal egg count in Syrian hamsters infected with the hookworm A. ceylanicum compared with untreated control animals. (B) The fecal egg count reduction was not accompanied by a reduction of worm load, which was not statistically significant between control and treated animals. (C) and

(D) RNAseq based gene expression profile over developmental stages of A. ceylanicum shows increased expression of CPT1/2 in adult female compared to L4 female, L4 male and adult male.

$215 \times 195 \mathrm{~mm}(300 \times 300 \mathrm{DPI})$ 